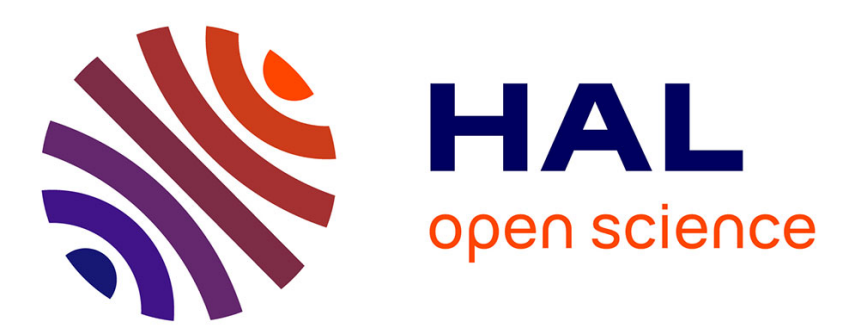

\title{
Duns Scot et la politique. Pouvoir du prince et conversion des juifs
}

Sylvain Piron, Elsa Marmursztejn

\section{To cite this version:}

Sylvain Piron, Elsa Marmursztejn. Duns Scot et la politique. Pouvoir du prince et conversion des juifs. O. Boulnois, E. Karger, J.-L. Solère, G. Sondag. Duns Scot à Paris, 1302-2002. Actes du colloque de Paris, 2-4 septembre 2002, Brepols, pp.21-62, 2004, FIDEM, Textes et études du Moyen Age, 26. halshs-00069741

\section{HAL Id: halshs-00069741 https://shs.hal.science/halshs-00069741}

Submitted on 19 May 2006

HAL is a multi-disciplinary open access archive for the deposit and dissemination of scientific research documents, whether they are published or not. The documents may come from teaching and research institutions in France or abroad, or from public or private research centers.
L'archive ouverte pluridisciplinaire HAL, est destinée au dépôt et à la diffusion de documents scientifiques de niveau recherche, publiés ou non, émanant des établissements d'enseignement et de recherche français ou étrangers, des laboratoires publics ou privés. 
Elsa Marmursztejn, Sylvain Piron

\section{DUNS SCOT ET LA POLITIQUE}

\section{POUVOIR DU PRINCE ET CONVERSION DES JUIFS}

[in Duns Scot à Paris, 1302-2002, O. Boulnois, E. Karger, J.-L. Solère, G. Sondag eds., Brepols, Turnhout (FIDEM, Textes et etudes du Moyen Age, 26), 2004, p. 21-62.]

D'un point de vue d'historiens, ce n'est pas tant l'entrée en fonction de Jean Duns Scot comme bachelier sententiaire à la faculté de théologie parisienne, à l'automne 1302, qui constitue un événement marquant; ce sont plutôt les circonstances dans lesquelles le futur maître a dû quitter Paris avant même la fin de l'année universitaire. L'exil auquel Duns Scot fut contraint, entre l'été 1303 et le printemps 1304, est la conséquence de son refus de souscrire à l'offensive lancée par le roi de France dans son conflit avec le pape. Comme on le verra, il s'agit là d'un choix proprement politique que l'œuvre savante du théologien franciscain ne suffit pas à éclairer. Sur un autre terrain, nous disposons en revanche d'un texte qui peut se lire comme une réflexion portant sur un événement politique majeur dont il fut également le témoin, l'expulsion des juifs d'Angleterre décidée par Edouard $\mathrm{I}^{\mathrm{er}}$ en juin 1290. C'est en fonction de ces deux points d'appui que l'on aimerait inciter à repenser la fonction et la place du politique dans la pensée de Scot. Celle-ci est généralement abordée à partir de son principal texte relevant expressément de la philosophie politique que forment les considérations sur l'origine de la propriété privée et du gouvernement civil, présentées en préalable à la question sur la restitution des biens mal acquis (IV Sent., dist. $15^{1}$ ). En l'approchant sous un autre angle, pour l'inscrire dans

${ }^{1}$ Voir en dernier lieu, John Duns Scotus, Political and Economic Philosophy, ed. \& tr. with an 
la situation politique de son temps, nous voudrions suggérer que l'essentiel de la pensée politique de Duns Scot est peut-être à chercher ailleurs que dans cette déduction des origines du pouvoir. Les années durant lesquelles s'est déroulée son activité intellectuelle ont vu se modifier radicalement l'équilibre des pouvoirs spirituels et politiques et leur emprise sur les sociétés occidentales. L'expulsion des juifs d'Angleterre, en 1290, et celle des juifs de France, en 1306, peuvent être considérées comme des indices notables de la cristallisation politico-religieuse que connaissent alors les deux principales monarchies d'Occident. Le bref texte dans lequel Scot s'exprime à ce sujet, à la première personne et de façon très singulière, offre un ancrage de première importance pour procéder, de façon plus large encore, à une mise en situation politique de sa pensée.

Au mois de juin 1303, au paroxysme de l'affrontement entre le roi de France et le pape, les universitaires parisiens furent à leur tour impliqués dans ce conflit. Dans l'escalade des répliques de Philippe le Bel aux affirmations de la primauté papale avancées par Boniface VIII, notamment dans la célèbre bulle Unam sanctam, l'assemblée tenue au Louvre le 13 juin marque une nouvelle étape. Lors d'une précédente réunion, au mois de mars, Guillaume de Nogaret avait qualifié le pape d'“ hérétique manifeste " et d'“ horrible simoniaque, tel qu'il n'y en a pas eu depuis le commencement du monde "; cette fois-ci, Guillaume de Plaisians dressait en vingt-neuf articles la liste infamante des hérésies professées par Boniface et des énormités qu'il avait commises, qui justifiaient sa déposition et son jugement par un concile général ${ }^{2}$. Le roi et ses conseillers entendaient de surcroît obtenir l'appui de l'ensemble des corps constituant le royaume. Les religieux résidant à Paris ou ailleurs dans le royaume furent ainsi mis en demeure d'apporter leur

introduction by A. WOLTER, St. Bonaventure (N.Y.), Franciscan Institute, 2000 et l'analyse de R. LAMBERTINI, “Aspetti etico-politici del pensiero di Duns Scoto ”, in Etica e persona. Giovanni Duns Scoto e suggestioni nel moderno, Bologna, Edizione francescane, 1994, p. 35-86, repris in ID., La povertà pensata, Modena, Mucchi, 1999, p. 111-139. Nous considérons par ailleurs qu'il n'existe aucun motif valable de tenir le traité De perfectione statuum pour une œuvre authentique de Duns Scot.

2 La plus récente édition de l'acte d'accusation figure in Boniface VIII en procès. Articles d'accusation et déposition des témoins (1303-1311), ed. critique, introduction et notes par J. CosTE, Roma, L'Erma di Bretschneider, 1995, p. 140-173. 
soutien à cette démarche, sous la menace de devoir quitter la France dans les trois jours. William Courtenay qui est récemment revenu sur cet épisode pour en tirer une image détaillée de la composition des couvents de religieux parisiens à cette date a souligné l'existence de deux types de documents ${ }^{3}$. Lors d'une première visite des agents du roi venus lire le texte de l'appel dans les couvents, un notaire dressa les listes des frères qui avaient alors, l'un après l'autre, déclaré leur assentiment ou exprimé leur opposition à l'appel. Après coup furent mises en forme des lettres de soutien dans lesquelles ne figuraient que les noms des frères favorables à la démarche du roi, laissant ainsi croire à une unanimité factice. Au sein du couvent franciscain, 68 frères acceptèrent de souscrire à l'appel tandis que 87 refusèrent. Parmi ces derniers figure le nom de Johannes Scotus accompagné de son socius Thomas.

La ligne de partage entre refus et adhésion recoupe pour l'essentiel la fidélité au roi de France. Dans leur très grande majorité, avec quelques exceptions notables comme celle du maître franciscain Jacques du Quesnoy ${ }^{4}$, les sujets de Philippe le Bel se rangèrent derrière leur souverain. En sens inverse, l'unanimité du refus est presque aussi forte parmi les Italiens et les ressortissants de l'Empire avec, là encore, quelques exceptions ou revirements entre les deux stades de la procédure. La situation est aussi complexe pour les autres nations. Ainsi, deux des trois franciscains irlandais qui avaient dans un premier temps refusé de souscrire à l'appel apparaissent sur la liste finale des soutiens au roi. Les alliances avec la France pèsent également, ce qui permet de comprendre la présence dans le même camp de quatre dominicains écossais. Comme le note W. Courtenay pour expliquer sa position contraire, John Duns est un "lowlander" qui a, de plus, été éduqué

\footnotetext{
3 W. J. Courtenay, "Between Pope and King: The Parisian Letters of Adhesion of 1303 ", Speculum 71 (1996), p. 577-605 ; ID., “ The Parisian Franciscan Community in 1303 ”, in Franciscan Studies, (1993), p. 155-171 ; ID., "Scotus at Paris", in Via Scoti. Methodologica ad mentem Joannis Duns Scoti, L. SILEO ed., Roma, Edizioni Antonianum, 1995, t. 1, p. 149-163.

4 Il est présenté dans cette liste comme magister jacobus de quarcheto Viromandia, ce qui permet d'exclure qu'il soit originaire de la ville du Quesnoy, place forte des comtes de Hainaut. Plusieurs toponymes identiques existent en Vermandois, le lieu le plus probable étant la commune actuelle de Parvillers-Le Quesnoy.
} 
en Angleterre. Et pourtant, même parmi les Anglais, le choix n'est pas unanime. On découvre ainsi que l'un des plus proches disciples de Scot, Guillaume d'Alnwick, donne son assentiment au roi dès la première étape, pour être rejoint dans la liste finale des soutiens franciscains par un Johannes de Anglia. Ce désaccord entre Duns Scot et son meilleur assistant permet également de faire remarquer que les positions théoriques n'ont pas simplement dicté leur règle. Il s'est agi d'un véritable choix personnel dans lequel ont pu entrer des considérations d'ordres divers dont l'une des moindres n'était sans doute pas la perspective de l'exil promis aux dissentientes.

Duns Scot n'a pas commenté sa décision. À aucun moment, dans ses cours ou ses écrits, il n'a livré de réflexion explicite sur les rapports entre les deux pouvoirs - royal et pontifical - qui permettrait de restituer l'arrière-plan de sa décision. Ephrem Longpré qui, le premier, a retrouvé le document attestant cette prise de position a intitulé l'article qu'il a consacré à cet épisode : “Pour le Saint-Siège, contre le gallicanisme ”. L'emploi d'un terme évidemment anachronique suffit à indiquer que cette interprétation ne fait qu'exprimer les propres convictions de l'historien franciscain. Depuis lors, les diverses tentatives qui ont été faites pour étayer cette interprétation n'ont pas donné de résultat probant. Le seul et bien faible indice qui ait pu être invoqué en ce sens tient au fait que "Boniface" soit cité, en tant qu'ayant promulgué le Liber Sextus, aussi bien dans l'Ordinatio que dans les reportata parisiensa ${ }^{6}$. En réalité, comme en convient Roberto Lambertini qui s'est posé la même question ${ }^{7}$, aucun texte ne permet de déterminer de façon univoque les motivations du choix fait par Duns Scot en 1303. Le refus de donner son assentiment à l'appel au Concile peut tenir à une multiplicité de facteurs entre

\footnotetext{
5 E. LONGPRÉ, “Le B. Duns Scot : pour le Saint-Siège, contre le gallicanisme (25-28 juin 1303)”, in $L a$ France franciscaine, 11 (1928), p. 137-162.

6 S. LoRENZINI, " Probabili motivi del rifiuto di G. Duns Scot ad aderire all'appello al concilio contro Bonifacio VIII ”, in Da Dante a Cosimo I, a cura di D. MASELlI., Pistoia, Tellini, 1976, p. 21-26.

7 R. LAMBERTINI, “ Il consenso della volontà : Filippo, Bonifacio e il pensiero politico del dottor sottile ", in Antropologia ed etica politica, a cura di G. LAURIOLA., Bari, Levante, 1995, p. 211-235, repris in La povertà pensata, op . cit.
} 
lesquels rien ne permet de trancher. Le point sur lequel nous pouvons en revanche insister est que cet acte ne signifie en rien une opposition de principe à la montée en puissance des monarchies territoriales, y compris en matière religieuse. De façon relativement imprévisible, c'est dans une distinction sur le baptême que le franciscain s'exprime le plus clairement à ce propos, dans des termes que l'on peut lire comme ceux d'une approbation de l'action d'Edouard Ier.

\section{La question du baptême forcé des enfants juifs}

Le document sur lequel nous voudrions nous attarder est une question de l'Ordinatio sur le quatrième livre des Sentences : "Faut-il baptiser les enfants des juifs et des infidèles contre le gré de leurs parents ?"8. Afin de démontrer la licéité de tels baptêmes, Duns Scot met en œuvre une argumentation exclusivement politique, invoquant le pouvoir que les princes chrétiens étaient en droit d'exercer sur leurs sujets non-chrétiens. L'enfance étant classiquement définie par les théologiens comme un état d'incapacité à exercer son libre arbitre - et donc à manifester sa volonté propre et à consentir au baptême -, l'enfant apparaît dans ce cas comme un enjeu de pouvoir. Il constitue plus précisément l'objet d'un conflit de droits, entre le ius patrie potestatis du parent juif et les droits du prince chrétien sur les juifs de son royaume. La condition juridique des juifs, à partir du XIIe siècle, avait été progressivement assimilée à celle des serfs, ce qui soumettait théoriquement leurs enfants à la volonté des seigneurs dont ils dépendaient ${ }^{9}$.

\footnotetext{
8 Ord. IV, d. 4, q. 9 : “Utrum parvuli Iudeorum et infidelium sint invitis parentibus baptizandi". Une édition de cette question est proposée en annexe. Les Reportata parisiensa ne contiennent pas les deux dernières brèves questions de la distinction 4 .

${ }^{9}$ Cette assimilation est le fruit d'une mutation insensible qui se produit à partir du XIIe siècle. Quoique jamais formellement établie, elle se traduit dans les chartes royales ou seigneuriales de France et d'Angleterre par la mention récurrente de Iudei nostri. Ce statut a notamment été officialisé à l'échelle d'une grande partie de la France par une ordonnance de Louis VIII datée de 1223. Cf. G. DAHAN, Les intellectuels chrétiens et les juifs au Moyen Age, Paris, Le Cerf, 1990, p. 67 ; ID., " Le pouvoir royal, l'Église et les juifs
} 


\section{Des décrétistes à Thomas d'Aquin}

Comme l'a montré en détail Gilbert Dahan dans les pages qu'il a consacrées à cette question $^{10}$, les premières discussions autour du baptême forcé des enfants juifs ont été formulées par les canonistes, à l'occasion de commentaires de textes d'époque wisigothique insérés dans le Décret de Gratien. Le canon 61 du concile de Tolède IV (633) stipulait que les enfants juifs, pour n'être pas davantage entraînés dans les erreurs de leurs parents, devaient leur être enlevés pour être confiés à un monastère ou à une famille chrétienne, où ils seraient élevés dans le culte chrétien ${ }^{11}$. Le précédent wisigoth, on le verra, a une certaine importance dans l'argumentation de Duns Scot. Mais pour leur part, les décrétistes, à l'instar d'Huguccio à la fin des années 1180 ou de Jean le Teutonique vers 1216, avaient donné de ce canon une interprétation défavorable aux baptêmes forcés. Deux arguments étayaient cette prise de position. Le premier prenait la forme de l'adage selon lequel il ne fallait faire d'injustice à personne (Nemini facienda est iniuria), en l'occurrence, ne pas porter préjudice aux parents juifs en leur enlevant leurs enfants pour empêcher qu'ils ne les élèvent dans l'erreur à laquelle le baptême était censé les arracher. Cet adage de droit naturel pouvait être de plus renforcé par une référence à la très importante bulle Sicut iudeis, publiée à de nombreuses reprises du XIIe au XIVe siècle, qui accordait aux juifs la protection pontificale, en réclamant qu'ils ne subissent aucun préjudice $^{12}$. Le second argument était lié au souci de ne pas faire obstacle, par l'assimilation complète des juifs à la société chrétienne, à l'accomplissement de la

ou de la condition politique des juifs dans l'Occident médiéval ", in Politique et religion dans le judaïsme ancien et médiéval, sous la dir. de D. TOLLET, Paris, Desclée, 1989, p. 85-107.

10 G. DAHAN, Les intellectuels chrétiens, p. 143-152.

11 Decretum Gratiani, 28, 1, 11 (ed. Friedberg, t. I, c. 1087) : “Iudeorum filios vel filias, ne parentum ultra involvantur erroribus, ab eorum consortio separari decernimus, deputatos aut monasteriis aut christianis mulieribus ac viris, Deum timentibus, ut sub eorum conversatione cultum fidei discant, atque melius instituti tam in moribus quam in fide proficiant". Pour sa part, Gilbert Dahan insiste surtout sur le canon 56 du même concile, Grat. 45, 5 (ed. Friedberg, c. 161-162) sur lequel on reviendra plus loin.

12 Sur l'histoire de ce texte, cf. S. GRAYZEL, "The Papal Bull Sicut Judeis", in Studies and Essays in Honor of A.A. Neuman, Leiden-Philadelphia, Brill-Dropsie College, 1962, p. 243-280. 
prophétie d'Isaïe, citée par saint Paul ${ }^{13}$, selon laquelle les “ restes d'Israël” se convertiraient à l'approche de la fin des temps ${ }^{14}$.

C'est dans la ligne de l'interprétation des décrétistes que se situait Thomas d'Aquin qui traita la question à deux reprises, dans un Quodlibet ${ }^{15}$, puis dans la Somme de Théologie ${ }^{16}$. Il faut noter que la question a précisément été introduite dans le champ du débat théologique par le maître dominicain. Sa détermination quodlibétique de 1269 coïncide chronologiquement avec la décision prise par Louis IX de rendre exécutoire la prescription du concile de Latran IV (1215) concernant le port de la rouelle ${ }^{17}$. En dépit du poids de ce contexte, la solution de Thomas d'Aquin vise à démontrer l'accord entre la coutume de l'Église et la loi naturelle exprimée par l'adage juridique selon lequel nemini facienda est iniuria ${ }^{18}$. Dans la mesure où, en termes aristotéliciens, l'enfant était “ naturellement quelque chose de son parent", il était naturel qu'il restât, jusqu'à l'âge de raison, " au soin de ses parents comme dans un sein spirituel "19. Cette norme fondée sur

13 Ro. 9, 27 : “Et pour ce qui est d'Israël, Isaie s'écrie : Quand le nombre des enfants d'Israël serait égal à celui du sable de la mer, il n'y en aura qu'un petit reste de sauvés".

14 Huguccio, Summa super Decretorum, Biblioteca Apostolica Vaticana, Borgh., fol. 161ra (cité par R.A. GAUTHIER in THOMAS D'AQUIN, Quodlibeta, Leon. XXV-2, p. 222) : "Quidam intelligunt hoc capitulum in eo casu cum ambo parentes sunt iudei et habent filios parvulos, qui auferendi sunt ab ei, ut dicunt, et debent baptizari. Set adulti non debent eis auferri, quia nullus cogendus est ad fidem, cum nullus possit salvari invitus. Set dico quod nec filii parvuli sunt eis auferendi, quia nulli est facienda iniuria. Ergo nec parentibus talium. Preterea, usque ad modicum tempus nulli essent iudei si hoc fieret; qualiter ergo reliquie Israel salve fierent in ultimis temporibus? Dico ergo quod hoc capitulum loquitur de filiis iudeorum baptizatis sive parvulis sive adultis, et presertim de illis qui circumcisi sunt a parentibus ex quo facti erant christiani ". Pour le second argument, voir également JoHANNES TeUtOnicus, Glossa ordinaria in Decretum, Rome, 1582, col. 2035.

15 ThOMAS D'AQUIN, Quodlibet II, 7 : “ Circa fidei sacramentum, utrum parvuli Iudeorum sint baptizandi invitis parentibus" (Leon., XXV-2, p. 221-224).

16 ID., Summa theologiae, IIa IIae, q. 10, a. 12, où Thomas d'Aquin reprend littéralement le contenu de sa détermination quodlibétique de 1269 (II, 7) ; IIIa, q. 68, a. 10.

17 Ordonnance de 1269 traduite par G. NAHON, "Les ordonnances de Saint Louis et les juifs ", Les Nouveaux Cahiers, 23 (1970), p. 29.

18 ThOMAS D'AQUIN, Quodlibet II, 7, (Leon. XXV-2, p. 223).

19 “Filius enim naturaliter est aliquid patris, et primo quidem a parente non distinguitur secundum corpus, quandiu in matris utero continetur; postmodum vero, postquam ex utero egreditur, ante quam usum liberi arbitrii habeat, continetur sub parentum cura sicut sub quodam spirituali utero " (ibid.). 
la justice naturelle n'admettait, en tant que telle, aucune dérogation. Thomas d'Aquin ajoutait qu'en soustrayant un enfant aux soins de son père, on agissait autant contre la justice dans l'ordre du droit naturel qu'en dérobant à leur propriétaire légitime un boeuf ou un cheval - aussi dépourvus de raison qu'un enfant - dans l'ordre du droit civil ${ }^{20}$.

C'est également l'opinion soutenue par le franciscain Richard de Mediavilla (de Menevyl, comme l'a récemment signalé le Père Bataillon ${ }^{21}$ ), qui fut régent en théologie à Paris au milieu des années $1280^{22}$. La solution qu'il propose s'inspire très manifestement des textes de Thomas d'Aquin sur la même question. Les arguments pro et contra exposés par les deux auteurs présentent en effet une large similitude. L'axiome selon lequel “il ne faut faire d'injustice à personne" est opposé, comme chez Thomas, au principe d'assistance aux personnes en "danger de mort spirituelle" ${ }^{23}$. La responsio proprement dite, qui s'appuie elle aussi sur la "coutume de l'Église", articule les deux arguments développés par Thomas, à savoir le periculum fidei et la iusticia naturalis : les enfants juifs baptisés de force et rendus à leurs parents seraient élevés, au péril de la foi, dans l'erreur et dans le mépris du sacrement reçu dans l'enfance ; en outre, un tel baptême bafouerait le droit que les parents exercent sur leurs enfants tant que ceux-ci sont incapables de faire usage de leur libre arbitre.

Toutefois, au cours de son raisonnement, Richard de Mediavilla introduit certaines

20 “Quandiu enim usum rationis non habet puer, non differt, quantum ad ea que agit, ab animali irrationali ; unde, sicut bos vel equs iure gentium vel civili est possessoris ut utatur eo cum voluerit sicut proprio instrumento, ita de iure naturali est quod filius, ante quam habeat usum rationis, sit sub cura patris " (ibid.)

21 L.-J. BATAILlON, “ Les nouvelles éditions critiques d'Henri de Gand et de Gilles de Rome ", in Revue des Sciences Philosophiques et Théologiques, 78 (1994), p. 425, n. 2.

22 Ricardus De Mediavilla, In IV Sent., d. 6, a. 3, q. 3, Brescia, apud Vincentium Sabbium,1591, repr. Frankfurt a. M., Minerva, 1963, p. 78-79 : “Utrum parvuli Iudaeorum et Paganorum sint invitis parentibus baptizandi ".

23 “ Magis subveniendum est homini contra periculum spiritualis mortis quam contra periculum mortis corporalis ; sed si aliquis non subveniret homini si posset contra periculum mortis corporalis, peccaret ; cum ergo parvuli Iudaeorum et Paganorum sint in periculo mortis spiritualis, nisi invitis parentibus baptizentur, videtur quod sint invitis parentibus baptizandi, ut sic eis subveniatur contra periculum mortis spiritualis [...] Contra : Nemini facienda est iniuria ; sed Iudaeis et Paganis fieret iniuria si parvuli eorum baptizarentur, quia quamdiu carent usu liberi arbitrii, sunt quasi parentum possessio et de iure sub eorum 
idées et formulations spécifiques qui seront reprises par Duns Scot, mais dans une perspective rigoureusement opposée. Il en va ainsi de l'argument, mentionné mais non retenu par Richard, selon lequel les enfants seraient davantage soumis au pouvoir de Dieu qu'à celui de leurs parents : “ L'enfant relève davantage du pouvoir de Dieu que de celui de ses parents charnels; il est donc juste qu'il soit soustrait à ses parents charnels pour être consacré, par le baptême, à son seigneur supérieur "24 Cette idée figurait déjà dans la liste d'arguments contradictoires élaborée par Thomas d'Aquin, mais elle y était exprimée dans des termes qui se référaient à une hiérarchie des ordres de la chair et de l'esprit $^{25}$. Pour sa part, Richard de Mediavilla emploie un vocabulaire différent, en parlant d'une hiérarchie de pouvoirs. Il ouvre ainsi la voie au développement d'un argumentaire spécifiquement politique que Duns Scot empruntera largement. Mais chez Richard, l'hypothèse d'un conflit de pouvoir, dont les instances se résument à deux termes, se trouve ainsi résolue : “ Bien que les enfants relèvent davantage du pouvoir de Dieu que de celui de leurs parents charnels, Dieu veut toutefois que les parents conservent, intact, le droit qu'ils possèdent sur le corps de leurs enfants; dans la mesure où ils conservent ce droit intact, baptiser [leurs enfants] contre leur volonté conduirait davantage, dans la plupart des cas, à déshonorer qu'à honorer le sacrement de la foi " ${ }^{26}$.

Ces pages apportent une autre inflexion importante à la démonstration de Thomas d'Aquin. Tandis que ce dernier n'envisageait à aucun moment l'éventualité que les enfants baptisés contre la volonté de leurs parents leur fussent enlevés, Richard construit toute sa responsio sur la distinction entre le cas où les enfants seraient rendus à leurs

cura ; ergo non sunt invitis parentibus baptizandi ", ibid.

24 “ Parvulus est magis sub dominio Dei quam parentum carnalibus. Ergo, iustum est ut subtrahatur a carnalibus, ut superiori domino per baptismum consecretur ", ibid.

25 Thomas D'AQuin, Quodlibet II, 7, Leon. XXV-2, p. 222 : “ Quilibet homo magis est Dei, a quo habet animam, quam patris carnalis, a quo habet corpus. Non ergo est iniustum si pueri Iudaeorum carnalibus parentibus auferantur et Deo per baptismum consecrentur. "

26 RiCARDUs DE MEDIAVILlA, loc. cit: “ Quamvis parvuli magis sint sub dominio Dei quam parentum carnalium, vult tamen Deus quod parentibus maneat ius salvum quod habent in corporibus parvulorum suorum, quo iure eis manente salvo, baptizare eos ipsis invitis magis esset, ut in pluribus, ad 
parents (qui les élèveraient dans l'erreur) et le cas où ils leurs seraient enlevés (au mépris de leur droit). Or les deux branches de la distinction ne s'opposent pas; elles se confortent mutuellement. Si la sauvegarde du droit des parents est conforme à la volonté de Dieu, le baptême forcé n'est rien d'autre qu'une occasion de déshonorer le sacrement. Le souci de concilier l'“ honneur du sacrement de la foi " et le respect du droit des parents débouche ainsi sur le refus des baptêmes forcés d'enfants. En intégrant la réfutation d'une objection théorique à l'encontre de l'argument du periculum fidei (car pour faire disparaître ce danger, ne suffisait-il pas que les enfants juifs baptisés fussent enlevés à leurs parents ?), Richard conforte et enrichit la solution Thomas. Mais les distinctions qu'il introduit se retrouveront, étoffées et assorties de conclusions contraires, chez Duns Scot qui avait vraisemblablement le texte de Richard sous les yeux lorsqu'il rédigea son propre texte ${ }^{27}$.

Duns Scot n'est toutefois pas le premier théologien à avoir adopté une position résolument favorable aux baptêmes forcés : à la fin du XIIe siècle, Pierre le Chantre, dans la troisième partie de sa Somme sur les sacrements ${ }^{28}$, se disait déjà “ très bouleversé et très étonné " de ce que l'Église ne baptise pas les enfants juifs et de ce que la volonté de leurs parents prévale en pareil cas, alors que le Christ avait souffert pour tous et voulu imprimer à tous le caractère du baptême, condition sine qua non du salut ${ }^{29}$. Duns Scot est

dehonorationem sacramenti fidei quam honorem."

27 Il semble ainsi que l'accent placé par Duns Scot sur la " cautela bona" que le prince devait observer en enlevant les enfants juifs baptisés à leurs parents soit une forme de réponse à l'argument que Richard invoque en ces termes, contre la séparation des parents et des enfants : "S'ils n'étaient pas rendus à leurs parents, on s'exposerait au danger que les parents les tuent en secret pour éviter qu'ils ne deviennent chrétiens".

28 PIERRE LE CHANTRE, Summa de sacramentis et animae consiliis, pars III, 2b, Liber casuum conscientiae, chap. 21, § 259, éd. J.-A. DugAuQUIER (Analecta Mediaevalia Namurcensia, 21). Louvain-Lille, Giard, 1967, spécialement p. 728. Le cas considéré par Pierre le Chantre est celui d'une femme juive qui, ayant jeté son dévolu sur un jeune chrétien et lui ayant promis devant témoin de se convertir, se trouvait enceinte et était détournée, par la malignité des juifs, de son projet de conversion ; qu'advenait-il de l'enfant en pareil cas ? Lequel de ses parents devait-il suivre?

29 PIERRE LE CHANTRE, loc. cit: " Ego moveor et multum miror, cum Christus sit passus pro omnibus et omnibus voluerit imprimi caracterem baptismi, sine quo non est salus, maxime parvuli decedenti, quod ecclesia non baptizat parvulos iudeorum, cum teneatur providere proximorum saluti, maxime in hiis que 
néanmoins le premier à avoir soutenu la licéité et la nécessité de ces baptêmes sur la base d'un argument politique distinct de celui de la servitude des juifs. Ce dernier argument avait déjà été utilisé à plusieurs reprises pour justifier que les enfants juifs baptisés fussent séparés de leurs parents. On le rencontre notamment dans le commentaire du dominicain Guillaume de Rennes sur la Somme de pénitence de Raymond de Peñafort, composé dans les années 1240 , dans un passage repris presque à la lettre au milieu du siècle dans le Speculum doctrinale de Vincent de Beauvais ${ }^{30}$, puis dans le commentaire sur les Sentences élaboré vers 1307-1308 par Durand de St-Pourçain ${ }^{31}$. Contre la thèse thomiste selon laquelle la servitude civile des juifs vis-à-vis des princes ne primait pas l'ordre du droit naturel ou divin ${ }^{32}$, Guillaume de Rennes exposait que "les princes, dont les juifs sont serfs, peuvent leur enlever leurs enfants sans leur porter préjudice puisqu'ils n'ont, en tant que serfs, aucun pouvoir" et que, "de même que les mêmes princes peuvent donner ou vendre les enfants [des juifs] en tant qu'esclaves contre la volonté de leurs parents, ils peuvent les offrir au baptême ; et cela serait méritoire, à condition toutefois qu'ils ne le fassent pas pour contraindre les parents à [embrasser] la foi, mais pour sauver leurs enfants par le sacrement de la foi qui est reçu pour autant qu'il ne se heurte pas à l'obstacle d'une volonté contraire" ${ }^{33}$. Si la position adoptée par Durand de Saint-Pourçain présente substantiellement le même contenu que celle de Guillaume de Rennes, le théologien enrichit toutefois l'argumentaire d'une distinction entre infidèles libres et non-libres : s'il n'était pas licite d'enlever et de faire baptiser de force les enfants des infidèles libres (par exemple les marchands infidèles de passage), car ce serait dérober le bien d'autrui et "offrir à Dieu le fruit d'une rapine", il était permis, en

sunt ad vitam eternam, et quare in hoc prevalet parentum prava voluntas? ”

30 Vincent De BeAuvais, Speculum doctrinale, lib. 9, c. 42, Douai, Belleri, 1624, t. II, c. 797.

31 Durand de SAINT-PourÇAIN, In IV Sent., d. 4, q. 6, Lyon, Gaspard de Portonari, 1556, fol. 260ra.

32 Thomas D'Aquin, Quodlibet II, 7, ed. cit., p. 224 : “ Ad tercium dicendum quod Iudei sunt servi principum servitute civili, que non excludit ordinem iuris naturalis vel divini ".

33 Guillaume De RenNes, in Summa Raymundi de Pennafort o. p. cum glossis, Avignon, Mallard, Delorme \& Chastanier, 1715, p. 45. 
revanche, de faire baptiser les enfants des juifs soumis aux princes en tant que serfs, à condition de les leur enlever préalablement ${ }^{34}$. La solution, radicale, se fonde sur la primauté de l'argument juridique de la servitude des juifs, mais s'en tient au seul cas des enfants.

\section{Duns Scot et la conversion forcée des juifs}

Pour Duns Scot, l'objection thomiste selon laquelle on ne pouvait commettre l'injustice d'enlever un enfant à ses parents valait sans doute pour une personne privée (de quacumque persona privata), mais pas pour le prince dont les infidèles étaient les sujets. L'unique argument avancé est celui de la hiérarchie des puissances qui réclame qu'un pouvoir supérieur s'impose, y compris en contrecarrant la volonté d'un pouvoir inférieur à l'égard de ses propres sujets. Un passage de saint Augustin, développant la formule célèbre de l'Epître aux Romains 13 (“ qui résiste au pouvoir, résiste à l'ordre de Dieu "), permet d'exemplifier cette imbrication des différents degrés de pouvoir ${ }^{35}$. Le postulat qui permet son application dans ce cas consiste à présenter le droit (ius dominii) dont dispose Dieu sur l'enfant dans un rapport de supériorité à celui que ses parents ont sur lui. À ce titre, puisque le prince doit par priorité servir Dieu, son seigneur suprême, il a non seulement la licence, mais le devoir (non solum licet, sed et debet) de soustraire leurs enfants à des parents qui voudraient les élever contre le culte de Dieu, précisément afin de les faire élever dans ce culte. Seul cet argument de la hiérarchie et de l'imbrication des puissances permet à Duns Scot de contourner l'objection thomiste selon laquelle la servitude civile des juifs vis-à-vis des princes n'était pas exclusive de l'ordre du droit divin ou naturel ${ }^{36}$. L'unique réserve apportée à ce devoir religieux du prince est que de tels enlèvements d'enfants soient menés avec prudence, c'est-à-dire en secret, afin que les

\footnotetext{
34 Durand De SAINT-PourÇAIN, In IV Sent., d. 4, q. 6, loc. cit.

35 Augustin, Sermo VII, 13 (PL 38, c. 420-421).

36 THOMAS D'AQUIN, Quodlibet II, 7, Leon. XXV-2, p. 224.
} 
parents, prévenus du projet, ne soient tentés, par désespoir, de mettre fin aux jours de leur progéniture, par une clause qui ne fait que répondre à l'objection soulevée par Richard de Mediavilla.

Mais Duns Scot ne s'en tient pas là. Il poursuit par une recommandation qui va ouvertement à l'encontre de l'interdiction canonique des baptêmes forcés d'adultes ${ }^{37}$. De plus, cette mise en cause - et cela mérite d'être souligné - se présente sous la forme d'une prise de position personnelle : “Qui plus est, je crois que l'on agirait de façon pieuse et religieuse, si l'on contraignait les parents eux-mêmes, par la menace et l'effroi (minis et terroribus), à recevoir le baptême et à le conserver une fois reçu parce que, même s'ils n'étaient pas véritablement fidèles en leur for intérieur, il serait cependant moins mauvais qu'ils ne puissent plus observer impunément leur loi illicite, plutôt qu'ils puissent l'observer librement. Et leurs fils, s'ils étaient bien éduqués, deviendraient de vrais fidèles en trois ou quatre générations ".

À l'argument de la prophétie d'Isaïe, Duns Scot répond en deux temps. Il y oppose tout d'abord une autre prophétie, fondée sur Jean, 5, 43 (“Qu'un autre vienne en son propre nom, celui-là vous le recevrez!"), qui permet d'annoncer que, dans une perspective apocalyptique, les juifs se convertiraient d'abord à l'Antéchrist. Ce n'est qu'une fois celui-ci détruit qu'interviendrait leur conversion finale qui ne concernerait donc qu'un tout petit nombre. La conclusion qui en est tirée se fonde sur d'étonnantes considérations démographiques ${ }^{38}$. Puisque cette conversion ne représentera qu'un “ fruit modique pour l'Église” et si tardif qu'il ne s'accroîtra d'aucune descendance, “il ne serait pas nécessaire de supporter que tant de juifs, dans tant de contrées du monde, pendant si longtemps, persistent à observer leur loi. Il suffirait que l'on permette à un petit nombre d'entre eux, mis à l'écart dans une île (aliquos paucos in aliqua insula sequestratos) d'observer leur loi, pour que la prophétie d'Isaïe puisse s'accomplir".

37 Decretum Gratiani, 45, 5 (ed. Friedberg,. I, 161-162) et Liber Extra, 5, 6, 9 (Friedberg II, 774).

38 Sur la "pensée démographique" médiévale, voir les perspectives nouvelles ouvertes par P. BILLER, The Measure of Multitude. Population in Medieval Thought, Oxford, Oxford University Press, 2000. 
Le seul argument d'autorité allégué par Duns Scot pour justifier la conversion forcée des adultes, dans le dernier paragraphe de la question, nous reconduit aux temps wisigothiques. L'exemple du roi Sisebut, qualifié de "prince très religieux" par le concile de Tolède pour avoir contraint des infidèles à recevoir le baptême, est l'unique point d'ancrage canonique invoqué en faveur de ce programme de conversion massive "par la menace et l'effroi". Cette référence est de plus employée en détournant expressément le sens d'un canon qui, dans son ensemble, loin de faire la louange du roi, cherchait surtout à régler le problème posé par son action intempestive : les juifs baptisés de force devraient conserver la foi chrétienne, mais l'exemple de Sisebut ne devait pas être imité ${ }^{39}$. Le recours de Duns Scot à cette unique autorité canonique signale bien la singularité de sa position et l'originalité d'un propos dont on ne trouve aucun équivalent avant lui. L'interprétation du canon wisigothique imposée par Innocent III dans la décrétale Maiores (1201) confirmait certes que les infidèles baptisés de force au temps de Sisebut dussent observer la foi chrétienne ${ }^{40}$; mais elle ne justifiait ni ne préconisait en aucun cas la pratique des baptêmes forcés d'adultes (quoiqu'elle en garantît les effets). Duns Scot est ainsi le premier et pratiquement le seul théologien médiéval qui ait prôné des baptêmes forcés d'adultes que le droit canonique prohibait explicitement. Singulier face à ces devanciers, Scot l'est aussi par rapport à ses contemporains. Ainsi, comme on

\footnotetext{
39 Ce détournement est notamment repéré par CAJETAN, Commentarius in Summam Theologiae, IIa IIae, q. 10, a. 8 : “Ad primum autem Scoti dicitur quod sententia synodi duo continet, scilicet laudem principis et prohibitionem facti. Et ex secundo patet quod non approbat factum. Ac per hoc insinuat quod laudatur princeps de intentione : multa enim mala intentione bona fiunt. " (Leon. VIII, 89)

40 Extra 3, 42, 3 (ed. Friedberg II, 646) : "Is, qui terroribus atque suppliciis violenter attrahitur, et, ne detrimentum incurrat, baptismi suscipit sacramentum, talis quidem, sicut et is, qui ficte ad baptismum accedit, characterem suscipit Christianitatis impressum, et ipse, tanquam conditionaliter volens, licet absolute non velit, cogendus est tamen ad observantiam fidei Christianae. In quo casu debet intelligi decretum illud concilii Toletani, ubi dicitur, quod, qui iam pridem ad Christianitatem coacti sunt, sicut factum est temporibus religiosissimi principis Sisebuti, quia iam constat eos sacramentis divinis associatos, et baptismi gratiam suscepisse, et chrismate unctos est, et corporis Domini exstitisse participes, oportet etiam, ut fidem, quam necessitate susceperunt, tenere cogantur, ne nomen Domini blasphemetur, et fides, quam susceperunt, vilis ac contemptibilis habeatur. Ille vero, qui nunquam consentit, sed penitus contradicit, nec rem, nec characterem suscipit sacramenti, quia plus est expresse contradicere quam minime consentire".
} 
l'a vu, Durand de Saint-Pourçain se prononce pour le baptême des enfants en fonction du seul argument de la servitude des juifs, sans envisager le cas des adultes ni celui de l'expulsion ou du cantonnement des juifs.

On pourrait être tenté de penser que les positions de l'un et de l'autre se rejoignent toutefois, et qu'elles accompagnent simplement, sur le plan théorique, la dégradation très nette de la condition des juifs au XIVe siècle. Deux textes contemporains infirment cette hypothèse. Dans son commentaire sur le quatrième livre des Sentences, le dominicain Pierre de la Palud aborde, entre 1310 et 1315, la question de savoir s'il faut baptiser ceux qui sont privés de l'usage de la raison ${ }^{41}$. Confrontant les arguments de Thomas d'Aquin et ceux de Durand de Saint-Pourçain, Pierre recentre la question sur la volonté de l'enfant et conclut que la "volonté interprétative" des parents infidèles doit l'emporter sur celle de l'Église, non parce que l'Église n'aurait pas le droit de baptiser leurs enfants (elle détient ce droit en vertu de la plénitude de sa puissance), mais parce que ce genre de baptême contrevient à la volonté de Dieu ${ }^{42}$. Les enfants des infidèles ne pourraient être baptisés que dans le cas où tous les liens naturels entretenus avec leur milieu d'origine seraient dénoués, par exemple si leurs parents étaient morts, si aucun proche parent n'avait pu les recueillir et si ceux auxquels ils auraient été confiés voulaient les faire baptiser $^{43}$.

Dans un texte issu du commentaire du carme catalan Guido Terreni sur le Décret de

41 Pierre De la PALUd, In IV Sent., d. 4, q. 4, a. 1, Paris, 1514, fol. 19 ra-20 vb.

42 “ Unde cum habeat plenitudinem potestatis in omni terra, et in omni homine eam habet, et sic nec parentes, nec ipsi se subiiciant, Deus tamen subiicit sibi omnem hominem. Unde non hoc facit defectus iuris, sed prohibitio superioris, unde et de aliis criminibus punit infideles, sed de isto non, quia Deus prohibet, cui coacta servitia non placent. Et si ecclesia potest de his qui foris sunt iudicare, sicut potest arcere infideles a communione fidelium propter peccatum in moribus, non propter peccatum in fide, quod est in eorum ritu" (ed. cit. fol. $20 \mathrm{va})$.

43 “ Et si quidem pater et mater iudei mortui essent, sicut aliquando pater moritur, relicta uxore pregnante, que etiam moritur in partu vel moriuntur antequam puer habeat usum rationis, tunc propinquiora de genere sunt tutores legitimi loco parentum. Unde non deberet nec posset baptizari ipsis invitis, sicut nec parentibus invitis. Sed si non apparent nec parentes, nec propinqui, loco parentum succedit quicumque vult. Et ideo quicumque vellet, posset eum tunc baptismo offerre, quia naturalis ratio dictat, ut cui parens deficit, alius parens sit, sicut una avis alios pullos nutrit quando mater deficit" (ed. cit. fol. 20 va-vb). 
Gratien (1339), on trouve également une position défavorable au baptême forcé d'enfants ${ }^{44}$. G. Dahan a observé que ce commentaire marquait dans l'ensemble une plus vive hostilité aux juifs que ceux des décrétistes des XIIe et XIIIe siècles. Cette radicalisation sensible se traduit en particulier par la récurrence du motif de la servitude des juifs, ainsi que par la position assez rigoureuse adoptée par le carme catalan à propos des baptêmes forcés d'adultes : seule la contrainte absolue (qui excluait la crainte de la mort, classée parmi les contraintes relatives) invalidait le baptême. Guido Terreni concluait toutefois qu'il ne fallait pas contraindre les juifs à recevoir le baptême, même de cette manière. Compte tenu de la ligne générale du commentaire, la position de son auteur quant aux baptêmes forcés d'enfants prend un relief particulier. Fondée sur l'argument thomiste du primat et de l'immutabilité du droit divin ou naturel ${ }^{45}$, la démonstration de Guido Terreni constitue en outre une réfutation de celle de Duns Scot qu'il paraphrase sans le nommer. Guido Terreni juge en effet “ fausse et erronée " l'opinion selon laquelle, dans le respect de la hiérarchie des puissances, le prince mettrait son pouvoir au service de Dieu en enlevant leurs enfants aux parents infidèles pour les faire baptiser et les faire élever dans le culte chrétien, et au-delà, en contraignant les juifs à recevoir le baptême “ par la menace et l'effroi ". Cette opinion est, dit-il, “ expressément contraire à ce que dit saint Augustin [...], à savoir qu'il ne faut pas contraindre ceux qui n'ont jamais reçu la foi ni le sacrement de la foi à les recevoir. Il faut les y amener en les y incitant par la prédication et par l'exhortation, non par la contrainte ". S'il faut contraindre " ceux qui dévient de la voie de la foi reçue " à rentrer dans le droit chemin, “ le prince ne doit pas contraindre les juifs qui n'ont jamais reçu la foi à recevoir le baptême "46. L'argument invoqué par Duns Scot est donc nul, “car Dieu n'ordonne ni dans l'Ancien ni dans le

\footnotetext{
44 Guido TerRenI, Commentarius super Decreto Gratiani, De consecratione, d. 4, c. 100, “Utrum parvuli Iudaeorum sint invitis parentibus baptizandi", ed. in B.F.M. XIBERTA, Guiu Terrena carmelita de Perpinya, Barcelone, 1932, p. 315-318.

45 " Unde iure divino et naturali filii sunt sub cura parentum, donec usum rationis habeant sic quod possint nolle et velle. Ita quod servitus inducta iure positivo non tollit ius divinum et naturale " (ed. cit., p. 316). 46 Ibid., p. 317.
} 
Nouveau testament que les enfants soient enlevés à leurs parents, bien au contraire ; il interdit en effet d'enlever à quiconque ce qui lui appartient et de faire injustice à quiconque [...]. Le prince ne doit chercher [à défendre] le droit et le pouvoir de Dieu que pour autant que Dieu le veuille. Or il ne veut pas être servi sous la contrainte "47. Guido Terreni réfutait dans les mêmes termes l'argument selon lequel "les fils et les descendants [des adultes convertis de force] deviendraient fidèles au bout de trois ou quatre générations ", car les baptêmes forcés d'adultes contreviennent à la volonté divine et les “ infidèles occultes, chrétiens en pure apparence, pourront exercer plus facilement leur séduction, et surtout sur leurs enfants, qui habitent avec eux, jusqu'à la troisième ou la quatrième génération "48. Guido Terreni formulait donc, en termes inspirés de Thomas, une critique vigoureuse de l'opinion de Duns Scot, dont il analysait tous les arguments et qu'il rejetait comme “ irrationnelle, insensée et contraire à toute la coutume de l'Église universelle "49 . Le débat semble, dès lors, s'être cristallisé dans l'opposition de deux opinions rigoureusement contradictoires : celle de Thomas d'Aquin et celle de Duns Scot.

Ce dernier apparaît en définitive comme le seul théologien de son époque qui ait préconisé la disparition presque complète des juifs par la conversion forcée. Seule la prophétie d'Isaïe, dont on a vu qu'il cherche à minorer le poids, lui inspire cette solution, à l'époque unique en son genre, de l'expulsion et du cantonnement des juifs “ dans une île " où ils continueraient d'observer leur loi. De ce point de vue, il s'agit bien d'un texte hors norme. Pour autant, sa ligne argumentative centrale n'entre pas en dissonance aigüe avec d'autres passages de Scot. Une précédente question, dans la même distinction, montre que le baptême d'un non-consentant qui ne proteste pas explicitement produit valablement son effet. Le cœur du raisonnement soutient que la volonté contrainte reste une volonté dans 1'absolu (simpliciter $)^{50}$. C'est ainsi que le marchand qui jette ses

\footnotetext{
47 Ibid., p. 318.

48 Ibid.

49 Ibid.

50 Dans cette exacte mesure, Duns Scot se situe dans la droite ligne de la décrétale Maiores citée plus haut,
} 
marchandises par-dessus bord pour sauver sa vie a bien voulu, dans l'absolu, jeter ses marchandises par-dessus bord, même s'il aurait préféré avoir la vie sauve sans perdre sa fortune ${ }^{51}$. La formule qui justifie que le dissentiens soit contraint d'observer la religion chrétienne correspond presque littéralement à celle qui est utilisée pour justifier les baptêmes forcés d'adultes : “c'est un moindre mal qu'il observe la loi chrétienne contre son gré, plutôt qu'il lui soit permis d'agir impunément contre elle, parce qu'il est moins mauvais de bien agir et de fuir le mal sous la contrainte que de mal agir et de fuir le bien librement et impunément " ${ }^{, 52}$. Mais s'il y a bien écho d'un texte à l'autre, la position vigoureuse prise au sujet du baptême d'un non-consentant ne suffit pas à expliquer le projet d'une conversion forcée systématique. Quant à l'argument de la hiérarchie des puissances qui fait le cœur de la démonstration, sa coloration scotiste est indéniable. C'est d'ailleurs expressément dans ces termes qu'Eugenio Randi résumait l'une des conséquences les plus remarquables de la doctrine de la toute-puissance chez Scot, qui pullule comme on le sait d'exemples de type juridico-politique : "Il existe donc une 'hiérarchie' de pouvoirs absolus, qui correspond à une échelle de dispositions croissantes, procédant de l'individu à Dieu [...] comme il existe, corrélativement, une échelle de puissances ordonnées " ${ }^{\prime 53}$. Toutefois, là encore, rien n'imposait a priori de projeter une

note 40 .

51 JEAN DUNS SCOT, Ord. IV d. 4, q. 4, Utrum non consentiens possit recipere effectum baptismi : “ Ille qui, ut fugiat aliquod incommodum, vult aliquid, simpliciter vult illud : sicut proiiciens merces in mare, ut fugiat submersionem, simpliciter vult proiicere merces. Nam potentiam suam motivam ad proiiciendum, voluntas movet imperando et ipsa seipsam libere movet, qui cogi non potest. Simpliciter ergo volens proiicit; sed secundum quid nolens, hoc est sub conditione nolens, quia nollet, si posset alio modo salvare vitam " (Wad. VIII, 237-238).

52 “Quantum ad iudicium Ecclesiae iudicantis de manifestis, et eum qui tacet praesumentis consentire, non cogetur reclamans ad observantiam religionis christianae; cogeretur autem non reclamans. Nec in hoc potest argui Ecclesia quod isti nolenti, tamen non reclamanti fiat iniuria. Minus enim malum est sibi quod invitus servet legem christianam quam quod impune permittatur agere contra eam, quia minus malum est invitum aliqua bona facere et mala fugere quam libere et impune mala agere et bona dimittere " (Wad. VIII, p. 238).

53 E. RANDI, Il sovrano e l'orologiaio. Due immagini di Dio nel dibattito sulla 'potentia absoluta' fra XIII e XIV secolo, Florence, Nuova Italia, 1987, p. 64. Les passages les plus importants sur ce point sont traduits par O. BoulNOIS, in La puissance et son ombre, Paris, Aubier, 1994, p. 267-285. 
telle articulation théologico-politique sur la question juive. Pour l'éclairer, nous voudrions proposer un retour sur l'événement qui a été, à notre sens, déterminant dans l'élaboration de cette position.

\section{Duns Scot et l'expulsion des juifs d'Angleterre}

Quelques mots d'historiographie ne sont pas inutiles à ce stade de l'enquête. Disponible et connu depuis longtemps, ce texte n'avait pourtant jusqu'à présent guère été mis en avant par les lecteurs de Duns Scot. Georges de Lagarde ne le signale qu'incidemment, dans une note qui ne le cite que partiellement et laisse dans l'ombre la suggestion finale de déportation des " restes" d'Israël ${ }^{54}$. On peut trouver des références plus détaillées à cette question dans les travaux portant sur l'attitude des intellectuels chrétiens face aux juifs, de la part de chercheurs tels que Guido Kisch, Solomon Grayzel, et en dernier lieu Gilbert Dahan ${ }^{55}$. Plus récemment, Robert Lerner l'a brièvement mentionnée, en contrepoint à un courant d'inspiration joachimite, moins hostile aux juifs, représenté par des auteurs comme Pierre de Jean Olivi ${ }^{56}$. Les pages que Luca Parisoli consacre à cette prise de position scotiste, " afin de montrer sa rationalité et la défendre contre toute accusation anachronique [d'intolérance] ", s'attardent davantage à contester la réplique de Guido Terreni qu'à rendre véritablement compte d'un texte dont le point le

\footnotetext{
54 G. de LAgARDE, La naissance de l'esprit lä̈que au déclin du Moyen Age, vol. 2, Secteur social de la scolastique, Paris-Louvain, Nauwelaerts, 1958 ( $2^{\mathrm{e}}$ éd.), p. 259.

55 G. KISCH, " Toleranz und Menschenwürde ”, in Judentum im Mittelalter (Miscellanea Mediaevalia 4), P. WiLPERT, W. P. ECKERT ed., Berlin, De Gruyter, 1966, p. 1-36 ; S. GraYZEL, " Popes, Jews, and Inquisition from Sicut to Turbato ", in Essays on the Occasion of the Seventieth Anniversary of the Dropsie University, Philadelphia, Dropsie College, 1979, p. 159-160 ; G. DAHAN, Les intellectuels chrétiens et les juifs, p. 149-150.

56 R. LERNER, The Feast of Saint Abraham. Medieval Millenarism and the Jews Philadelphia, University of Pennsylvania Press, 2001, p. 4.
} 
plus choquant (le cantonnement sur l'île) est encore une fois passé sous silence ${ }^{57}$. Cette ligne de défense qui cherche à édulcorer les documents et à minimiser les faits est évidemment inacceptable. Elle traduit à sa façon un embarras qui a longtemps régné dans l'historiographie quant à la situation des juifs dans l'Occident médiéval. Il y a une douzaine d'années de cela, Colin Richmond a dressé l'inventaire détaillé des oublis et des omissions dont les médiévistes anglais se sont rendus coupables sur ce point, en faisant apparaître par contraste l'importance qu'a révêtue l'hostilité envers les juifs, fantasmatique ou traduite en actes, dans l'histoire anglaise des XIIe et XIIIe siècles ${ }^{58}$. Le royaume d'Angleterre se distingue en effet par la précocité de manifestations d'anti-judaïsme caractéristiques de l'Europe de la fin du Moyen Age : les accusations de meurtres rituel d'enfants chrétiens, apparues au milieu du XIIe siècle, se prolongent un siècle plus tard par le culte du " petit saint Hugues de Lincoln ", censé avoir été crucifié par un juif. Les massacres d'York, en 1190, ont pour conséquence de placer des juifs sous le contrôle étroit de l'administration royale, qui crée à cette fin un "Echiquier des juifs ". L'expulsion totale et définitive des juifs du royaume vient elle-même s'ajouter à plusieurs expulsions partielles, de telle ou telle ville, mais qui se voulaient déjà définitives. Bien que l'historiographie anglaise ait depuis lors largement corrigée ses lacunes, la question de Duns Scot sur le baptême forcé pourrait encore venir compléter le tableau dressé par C. Richmond. Il est en tout cas nécessaire, pour saisir les ressorts de ce texte, de le replacer au sein de cette histoire anglaise dont il constitue presque l'ultime maillon médiéval.

La résolution singulière de cette question sur le baptême forcé ne paraît en effet prendre sens qu'en étant mise en relation avec la politique royale anglaise à l'égard des juifs, dont le dernier acte fut l'expulsion de l'ensemble de la communauté (environ 2000 personnes), décidée le 18 juin, proclamée le 18 juillet et effective au 1er novembre 1290.

57 L. PARISOLI, La philosophie normative de Jean Duns Scot. Droit et politique du droit, Roma, Istituto Storico dei Cappuccini, 2001, p. 92-98.

58 C. RichMOND, “Englishness and Medieval Anglo-Jewry”, in Immigrants and Minorities, 10 (1991) p. 42-59. Nous tenons à remercier Peter Biller de nous avoir fait connaître ce texte important. 
Lorsque, moins de dix ans plus tard à Oxford, Duns Scot fait surgir, d'une façon inédite et insolite au sein de la réflexion théologique médiévale, la perspective d'un " isolement" des juifs, on est fondé à penser que cet événement était non seulement présent à son esprit, mais plus encore, qu'il constituait l'horizon immédiat de sa réflexion.

Dans leurs études récentes sur la question, des historiens comme Robert Stacey ou Robin Mundill ${ }^{59}$ ont en partie expliqué l'expulsion générale de 1290 comme conséquence de l'échec d'une politique royale de conversion initiée au début des années $1230^{60}$. La fondation à Londres par Henri III, en 1232, de la domus conversorum, traduisait emblématiquement ce projet. Dédiée à la Vierge, cette " maison des convertis" était conçue et organisée comme un monastère, où des "frères" (hommes, femmes, enfants) menaient une vie commune rythmée par des offices religieux quotidiens, célébrés par des chapelains qui étaient eux-mêmes des convertis. Robert Stacey a mis en évidence l'attachement des juifs convertis à ce monde clos, à cet “ entre-deux " situé à la charnière des sociétés juive et chrétienne, qui leur épargnait les périls d'une intégration réelle. L'institution, subventionnée par le souverain, manifeste tout l'intérêt porté aux conversions dans un contexte où les dominicains, arrivés en Angleterre dans les années 1220, déployaient simultanément des efforts significatifs en ce sens ${ }^{61}$.

Or après un pic de conversions atteint dans les années 1240-1250, l'entreprise marque le pas. Le nombre des conversions diminue nettement sous le règne d'Edouard Ier, moins marqué par la volonté de convertir que par la crainte de voir apostasier les convertis et par des persécutions sanglantes. Robert Stacey évoque à ce propos une “grande peur”, enracinée dans le contexte de la guerre des barons (1263-1265) qui fut

59 R. STACEY, “ The Conversion of Jews to Christianity in Thirteenth Century England ", Speculum, 67 (1992), p. 263-283 ; R. R. MuNDILL, England's Jewish Solution. and Expulsion, 1262-1290, Cambridge, Cambridge University Press, 1998.

60 “ Comme en France, la frustration liée à l'échec de ces efforts de conversion doit avoir joué un rôle dans la décision d'expulser toute la communauté juive d'Angleterre en 1290 ”, R. STACEY, op. cit., p. 282.

61 R. STACEY, ibid., note que les Dominicains se sont installés à proximité du quartier juif ; il souligne en particulier le rôle de Robert Bacon qui encourage les conversions, prend des convertis sous sa protection, en 
l'occasion d'un certain nombre de conversions opportunistes (la conversion apparaissant comme la seule solution pour échapper au meurtre), et qui s'exprime à travers les massacres de 1278-1279 62 . Dans un registre différent, on peut signaler l'obligation faite aux juifs, à partir de janvier 1280, d'assister chaque semaine aux sermons sur la conversion prêchés par les dominicains ${ }^{63}$. Mais on trouve aussi des échos répétés de cette inquiétude du côté de la papauté. La bulle Turbato corde, promulguée par Clément IV en 1267 qui plaçait les relaps sous l'autorité de l'Inquisition, est ainsi réitérée quatre fois de suite en quelques années. L'apostasie des juifs convertis semble bien être devenue un réel sujet d'inquiétude dans les cercles du pouvoir anglais, dans les années 1280, comme en témoigne de manière éloquente l'enquête réclamée en 1281-1283 par Jean Pecham, archevêque de Canterbury, au sujet d'une groupe de convertis londoniens ${ }^{64}$.

La crainte de l'apostasie exprimait clairement l'échec de la politique de conversion : plusieurs décennies de soutien royal à la domus conversorum, de sermons dominicains et de lourdes taxations n'avaient pas réussi à élever le nombre de baptêmes à plus de quelques centaines. Peu de temps avant l'expulsion, en 1290, deux événements viennent en particulier corroborer ce constat d'échec : à Oxford, un converti qui prélevait une taxe destinée à subventionner la domus conversorum fut violemment pris à partie par des juifs (il s'agit en l'occurrence d'un des rares cas d'émeutes juives relatés par les sources) ${ }^{65}$; la même année, les juifs de Londres protestèrent avec véhémence contre le baptême d'un enfant juif à l'église de Saint-Clément, au motif qu'ils n'y avaient pas consenti ${ }^{66}$. L'émeute des juifs d'Oxford, comme la protestation des juifs de Londres, expriment bien

conduit certains à la prêtrise.

62 Cf. Z. ROKEAH, "Money and the Hangman in Late-13th-Century England ", in Jewish Historical Studies, 31 (1988-90), p. 83-109.

63 R. R. MUNDILL, op. cit., p. 274.

64 F. D. Logan, “ Thirteen London Jews and Conversion to Christianity : Problems of Apostasy in the 1280's", in Bulletin of the Institute of Historical Research, 45 (1972), p. 214-229.

65 V. D. LIPMAN, “ The Anatomy of Medieval Anglo-Jewry ", in Transactions of the Jewish Historical Society of England, 21 (1968), p. 64. 
le rejet ou le refus de la conversion auquel se heurte en définitive la politique royale.

Celle-ci s'est du reste infléchie dès le milieu des années 1270, comme l'atteste le Statutum de Judeismo de $1275^{67}$. Il s'agit du premier acte de la législation relative aux juifs du règne d'Edouard $\mathrm{I}^{\mathrm{er}}$, et aussi du document le plus détaillé et le plus radical de toute la législation du XIIIe siècle concernant les juifs. Ce statut, qui mettait en application les dispositions du concile de Lyon (1274) en leur interdisant de pratiquer le prêt à intérêt et la prise de gages, stipulait en outre l'expulsion des juifs des villages normands ${ }^{68}$ et imposait le port d'un insigne distinctif à tous les juifs âgés de plus de sept ans. Le souverain anglais n'avait toutefois pas abandonné tout espoir de conversion, puisqu'à la même date, il donnait l'ordre d'agrandir la domus conversorum de Londres.

Les années 1280 sont également marquées par un changement d'attitude de la papauté à l'égard des juifs. Cette évolution est notamment perceptible dans une lettre qu'Honorius IV adressa en 1286 aux archevêques de Canterbury et d'York ${ }^{69}$ : le pape y dénonçait les actes horribles commis par les juifs à l'encontre de Dieu et de la foi chrétienne et condamnait en particulier leurs tentatives pour circonvenir les convertis et séduire les chrétiens ; il mettait en cause l'efficacité du clergé anglais qui avait échoué à mettre un terme à ces abus. Cette lettre pontificale donna vraisemblablement un élan nouveau à la campagne religieuse conduite contre les juifs d'Angleterre, dans laquelle certains prélats étaient déjà largement engagés. Ainsi, en 1278, l'évêque de Lincoln Richard de Gravesend avait excommunié treize chrétiens employés par des juifs et fait procéder à l'arrestation d'un certain nombre de domestiques et de nourrices. À la différence de son prédécesseur, Robert Kilwardby, qui s'était montré plus soucieux de promouvoir les dominicains que de s'en prendre aux juifs - qu'il comptait convertir grâce à l'argumentation théologique et à la prédication -, Jean Pecham, qui avait accédé à la tête

\footnotetext{
66 Cf. Rotuli Parliamentorum, vol. I, p. 46, n 7, cité par R. R. MUNDILL, op. cit., p. 276, n. 168).

${ }^{67}$ Le texte de ce statut est traduit par R. R. MuNDILL, op. cit., p. 291-293.

68 Le décret est enregistré en avril 1276 par l'Échiquier de Normandie.
} 
de l'archevêché de Canterbury en 1279, illustre tout particulièrement le changement d'attitude de l'Église anglaise vis-à-vis des juifs dans les années 1280. Il avait notamment entretenu des contacts secrets avec l'évêque de Londres, en juillet 1281, dans le but d'interrompre la construction d'une synagogue; en août 1282, il ordonna au même évêque de faire détruire toutes les synagogues londoniennes à l'exception d'une seule ; en 1285, il se plaignit au Parlement de l'incapacité de la cour à lutter contre le mal juif et fit des remontrances à la reine qui tirait profit de l'usure juive ${ }^{70}$.

L'échec du projet de conversion, doublé de celui de la "réforme" des juifs par le statut de 1275, déboucha sur l'expulsion des juifs d'Angleterre en 1290. Mais cette décision ne fait pas figure d'exception dans le contexte des années 1280-1300. Elle doit être reliée à une série d'expulsions régionales, inaugurée par Edouard Ier lui-même, qui ordonna en 1287 le départ des juifs de Gascogne ${ }^{71}$. À cette occasion, les biens des juifs avaient été saisis, mais la majeure partie du produit de ces extorsions avait été distribuée à l'Église, en particulier aux Mendiants, et l'opération avait fort peu profité au roi ${ }^{72}$. En 1289, c'est Charles II, roi de Naples et de Sicile et neveu de saint Louis, qui expulsa les juifs de ses comtés d'Anjou et du Maine. Cette expulsion fut l'occasion d'une innovation importante car les sujets de Charles d'Anjou lui concédèrent une taxe destinée à compenser la perte par le souverain d'une source importante de revenus ${ }^{73}$. Le même procédé est appliqué par Edouard Ier en 1290, comme il le sera à la suite de l'expulsion

69 Cf. R. R. MundiLl, op. cit., p. 272.

70 Ibid., p. 273.

71 C'est la date retenue par les études les plus récentes. Voir notamment R. C. STACEY, "Thirteenth Century Anglo-Jewry and the Problem of Expulsion ", in Y. KaPLAN, D. KATZ eds, Expulsion and Resettlement, Jérusalem, 1992, p. 9-25 ; R. R. MUNDILL, op. cit., p. 276.

72 Cf. R. R. MundiLl, op. cit., p. 281.

73 Charles II se vit concéder une taxe de trois sous par feu par une assemblée de prélats et de nobles. Cf. J. StraYer, Studies in Early French Taxation, Westport (Conn.), Greenwood, 1972, p. 19 ; R. ChAZAN, Medieval Jewry in Northern France. A Political and Social History, Baltimore, Johns Hopkins University Press, 1973, p. 186. 
des juifs de Poitou et de Saintonge par Philippe le Bel en juillet $1291^{74}$.

Cet aspect financier a été mis en avant dans l'interprétation de l'expulsion donnée par Robert Stacey : en 1290, Edouard I ${ }^{e r}$ aurait opté pour l'expulsion des juifs parce qu'il savait pouvoir obtenir davantage des subsides levés sur ses sujets que d'une taille imposée aux juifs. L'expulsion serait intervenue à titre d'argument dans la négociation entre le souverain et la " nation " qui s'est affirmée, comme telle, au XIIIe siècle ${ }^{75}$. Dans le même ordre d'idée, R. Mundill a noté que les difficultés rencontrées par Edouard Ier, surtout à partir de 1283, pour obtenir que des décimes fussent levées à son profit, s'évanouirent juste après l'expulsion des juifs. À la fin de l'année 1290, le clergé anglais concéda ainsi une nouvelle décime au souverain qui la demandait ${ }^{76}$. Mais R. Mundill plaide néanmoins en faveur d'une interprétation de l'expulsion comme résultant d'une pluralité de facteurs, qui concourent à une évolution résumée en ces termes par William Jordan : "In location after location on the borderlands of France, princes and their consellors were abandoning the policy, dear to Saint Louis, of attempting to coerce Jews to convert by means of economic and social disabilities and were offering them instead a starker choice : convert or depart $"$ "77.

Duns Scot n'ignore évidemment pas ces différents épisodes ; il a probablement été le témoin direct de certains et assurément du dernier d'entre eux. Jusqu'en 1290, il existait une communauté juive à Oxford qui entretenait des relations intellectuelles et économiques avec l'université ${ }^{78}$. Sans vouloir lire sa question sur le baptême forcé comme une pure et simple apologie de l'expulsion, on doit reconnaître qu'elle n'a de sens qu'en fonction de cet événement. Le texte prend en effet pour prémisse un axiome qui

\footnotetext{
74 Cf. Archives Historiques du Poitou, 44 (1923), t. I, CXLVII, p. 227.

75 Cf. R. STACEY, “ Thirteenth Century Anglo-Jewry... ”, art. cit. p. 2.

76 Cf. R. R. MUNDILL, op. cit., p. 274.

77 W. C. JORDAn, The French Monarchy and the Jews, Philadelphia, University of Pennsylvania Press, 1989 , p. 180.

78 C. Rотн, The Jews of Medieval Oxford, Oxford, Clarendon Press, 1951.
} 
correspond à la situation historique créée par l'expulsion et qui n'est alors réalisée dans aucun autre royaume occidental: tous les sujets d'un prince chrétien doivent être eux-même chrétiens, fût-ce en apparence. La proposition ne laisse aux juifs résidant en terre chrétienne que le choix entre la conversion et l'exil. Dans une question portant sur le baptême, le théologien n'examine que la première option mais les deux branches de l'alternative sont solidaires. Si le prince chrétien a le devoir de convertir les juifs de son royaume, leur expulsion est la seule issue possible s'ils refusent de recevoir le baptême. L'extension de cette séquence logique à tous les royaumes chrétiens debouche sur la mesure d'isolement radical préconisée par Duns Scot, le cantonnement dans 1' "île" traduisant symboliquement la mise à l'écart des juifs et l'absence de tout contact avec la chrétienté. Plusieurs indices permettraient peut être d'associer encore plus étroitement ce texte à l'événement qui le sous-tend et au contexte de la politique royale anglaise dans son ensemble. On peut ainsi se demander dans quelle mesure le choix de remettre au goût du jour les projets d'éducation chrétienne d'enfants juifs enlevés à leur parents pourrait se comprendre comme un écho au modèle de la domus conversorum; de même, le scepticisme quant au nombre de générations nécessaires pour conduire les convertis à une foi sincère pourrait apparaître comme un aveu des difficultés recontrées par le projet de conversion. Mais plus encore, le choix de la seule autorité sur laquelle s'appuie Duns Scot pourrait bien suffire à révéler la signification implicite de ce passage. Le fait de donner en exemple un roi wisigoth qui par excès de zèle était allé au-delà des normes canoniques pourrait aisément se lire comme l'évocation de l'action récente d'Edouard $\mathrm{I}^{\mathrm{er}}$, nouveau Sisebut.

L'examen auquel on vient de procéder n'apporte aucune indication qui aiderait directement à expliquer le choix de 1303. Il est toutefois frappant de noter que Duns Scot prend ici une position très forte - et très inhabituelle - en faveur du pouvoir du Prince en matière religieuse. Là où Thomas d'Aquin et Richard de Mediavilla avaient argué de la “coutume de l'Église” pour rejeter les baptêmes forcés, Duns Scot invoque le devoir du souverain. Rien n'est dit dans ce texte d'un pouvoir supérieur éventuel qui pourrait venir 
s'interposer entre le roi et Dieu. La “ hiérarchie des puissances" est décrite d'une façon qui ne laisse guère de place au pape, et le rôle traditionnel de protecteur des juifs que jouait celui-ci depuis le début du XIIe siècle est totalement ignoré. La bulle Sicut Iudeis, principale expression de cette protection, est passée sous silence. L'ensemble des éléments présentés nous autorise donc à formuler au moins une hypothèse supplémentaire pour expliquer les motifs possibles de son opposition à Philippe le Bel. Outre les fidélités au pape, à l'Église et à l'ordre franciscain, et peut-être même davantage qu'elles, sa fidélité envers son propre souverain, Edouard Ier d'Angleterre, a pu jouer un rôle déterminant dans la décision prise le 25 juin 1303.

Les résultats qu'apporte cette mise en relation d'un écrit doctrinal et de l'événement qui en constitue l'arrière-plan doit inciter les historiens à renouveler les questions qu'ils adressent aux philosophes. Une opération de contextualisation bien menée peut en effet apporter un surcroît d'intelligibilité à chacun des termes qu'elle met en présence, aussi bien à une réflexion, si abstraite soit-elle, qu'à l'horizon historique sur le fond duquel elle s'élève. Sans qu'il y ait donc lieu de postuler des causalités univoques ou des déterminations immédiates, il faudrait du moins se demander si la rupture que constitue la pensée de Scot dans l'histoire de la métaphysique n'entretient pas des rapports étroits avec la mutation qualitative que connaissent, à la même date, les monarchies occidentales. La formule exacte de ce changement est encore peu claire, en dépit de nombreux signes, bien connus, de transformation profonde. Ce moment d'histoire pourrait gagner à être abordé sous l'angle de ses implications métaphysiques. Et dans un tel cadre d'analyse, nul doute que Duns Scot doit tenir une place centrale.

\section{Remarques sur la postérité du texte}

Dans ses commentaires qui accompagnent l'édition des questions sur le quatrième 
livre des Sentences procurée par Luke Wadding, Anthony Hickey formule deux remarques qui méritaient que soit menée, à titre exploratoire, une courte enquête sur la postérité de ce texte. Le franciscain irlandais signale d'une part que la doctrine énoncée dans cette question aurait été communément soutenue par les disciples de $\operatorname{Scot}^{79}$ et qu'elle aurait, d'autre part, été mise en œuvre par les Rois catholiques lors de l'expulsion des juifs d'Espagne. La nuance, de grande importance, qu'introduit à ce propos Hickey pour faire explicitement apparaître la perspective de l'expulsion, porte sur l'interprétation de la formule “ par la menace et l'effroi ". Il ne peut s'agir, de la part du pouvoir civil, que de menaces en matière civile et non pas de menaces de mort. Autrement dit, la seule menace concevable serait celle de l'exil ${ }^{80}$.

S'il est possible qu'au XVIIe siècle, cette doctrine ait constitué l'un des nombreux points caractérisant l'appartenance à une école “ scotiste", tel n'était assurément pas le cas pour les premiers élèves et disciples du maître. Pour sa part, François de Meyronnes ne soulève pas même le problème du baptême forcé, mais ce silence n'autorise à tirer aucune conclusion sur son sentiment à l'égard de la méthode prônée par $\operatorname{Scot}^{81}$. Dans la question unique qu'il pose au sujet du baptême, Jean de Bassoles ne traite pas davantage ce cas. On peut toutefois noter qu'il met fortement en avant le principe de la nullité du baptême d'un dissentiens absolu, reprenant en les accentuant davantage les propres mots de Scot à ce sujet; mais là encore, cette accentuation ne doit pas nécessairement être interprétée comme une désapprobation implicite de la thèse sur les baptêmes forcés ${ }^{82}$.

79 A. HicQuaEus, Commentarius in Ord. IV, 4, 9, (Wad. VIII) p. 276 : " Doctor [...] quem in praesenti quaestione sequuntur omnes eius discipuli"; ibid., p. 280 : "Habemus etiam exemplum Ferdinandi Catholici \& aliorum regum Hispaniae qui Mauros et Iudaeos compulerunt ad Baptismum, inter quos non est dubium fuisse multos invitos ad baptismum proprium et filiorum ".

80 Ibid., "Sed tantum intelligendum dico esse Doctorem de minis et terroribus in materia civili, et exilio, non autem in iis minis quae tendunt ad mortem corporalem."

81 Francois de MeYronNes, In quatuor libros Sententiarum, Venise, O. Scoti, 1520, fol. 181.

82 JEAN DE BASSOLES, In quartum Sententiarum, Paris, Regnault \& Frellon, 1516, fol. 24rb : “Et primo dico de voluntario simpliciter, qui omnino dissentit, ita quod nulla ratione consentit, sed potius omnino dissentit, quod illud non recipit aliquem effectum baptismii spiritualem. Deus enim non vult aliquem ascribere militie sue nec esse de familia sua invitum. Non vult enim coacta servitia ". 
Parmi les franciscains des premières décennies du XIVe siècles dont les commentaires du quatrième livre sont facilement accessibles, seul Pierre Auriol affronte directement la question. Après avoir rapporté textuellement l'opinion de Thomas et celle que défendait le Docteur Subtil, il incline expressément pour la première, en l'absence de toute disposition contraire prise par l'Église. Si celle-ci avait eu le devoir de contraindre les juifs au baptême, il eût été criminel de sa part de négliger, de fait, le salut de tant d'âmes. Pourtant, la formule qui vient clore ce paragraphe nuance considérablement le propos, et c'est sans doute en raison de cette phrase qu'Auriol est parfois cité parmi ceux qui ont adhéré à la doctrine scotiste : "Je considère toutefois que celui qui, par piété pour la foi, agirait en sens inverse, ne pécherait pas gravement $" 83$. Ce sont en revanche des propos sans ambigüité que tient, dans la seconde moitié du XVe siècle, un scotiste influent de la province d'Aquitaine, Gui de Briançon, pour qui la position de Richard de Mediavilla est ici la "plus sûre". Sa démonstration invoque notamment le principe de la protection des juifs, en citant sur ce point la décrétale Sicut Iudeis ${ }^{84}$. Aux mêmes dates, le franciscain angevin Nicolas d'Orbelles, suivant plus fidèlement la leçon de Duns Scot, intègre littéralement dans son résumé l'ensemble de la question, jusqu'à la suggestion finale de la déportation dans une île ${ }^{85}$.

\footnotetext{
83 PIERRE AURIOL, Commentarium in quartum librum sententiarum, Roma, Zanetti, 1605, fol. 56rb : " Pro ista autem opinione, quae iustitiae innititur, potest ratio una adduci ; si enim esset illud licitum, ut alii dicunt, imo secundum eos congruum, quare Ecclesia Romana nullum super hoc praeceptum legibus, et principibus hactenus promulgavit ; nec enim potuit sine culpae periculo tot, quot baptizati fuissent, salus negligi animarum. Ideo ad quaestionem respondeo quia aliud est, utrum Principes ad hoc teneantur, et aliud est, utrum hoc eis liceat de bono et aequo. Certum est quod non tenentur, sed utrum eis liceat est dubium, praecipue autem movet me ratio illa de Ecclesia, quomodo tantam salutem neglexisset, propter quod magis declino ad rigorem iustitiae quia parvuli possessio sunt parentum. Puto tamen quod qui pietate fidei motus oppositum faceret, non multum graviter peccaret. " La question a également été abordée au début du XIVe siècle dans le deuxième Quodlibet de Petrus Sutton, mais seul le titre en est conservé " Utrum parvuli Iudeorum sint baptizandi inivitis parentibus", cf. Girard J. Etzkorn, " Petrus Sutton (?) O.F.M. Quodlibeta ", in Franciscan Studies, 23 (1963), p. 72-139.

84 GUI DE BRIANCON, Collectarium super quartum sententiarum, Lyon, Baland, 1512, fol. 39va : "Quomodo autem, si principes possint inviti iudeis ipsos convocare ad baptismum ecclesia neglexisset tantam salutem? sed ecclesia docta spiritu sancto nullum coactum vult habere discipulum [...] immo ecclesia prohibet ne fiat ei aliqua iniuri; ut patet extra de iudeis et sarracenis, capitulo Sicut iudei ".

85 NiCOLAS D'ORBELLES, In quartum Sententiarum, Paris, Balligaut, 1498, fol. 12.
} 
La brève enquête que nous avons pu mener dans la scolastique tardive sur la façon dont ces pages de Duns Scot ont été reprises, citées ou contestées, demande à être poursuivie. De prime abord, il semblerait que vers la fin du XVe siècle, la ligne de partage sur la question du baptême forcé des enfants juifs ait été moins doctrinale que géographique. Si le problème ne présentait guère d'enjeux pratiques dans un royaume de France d'où les populations juives avaient été définitivement chassées à la fin du XIVe siècle, il n'en allait pas de même dans la vallée du Rhin où l'on rencontre des partisans des baptêmes forcés qui prennent appui sur Scot sans pour autant figurer au catalogue de ses disciples. Il en va ainsi du plus fameux théologien de la région, Gabriel Biel, qui, à Tübingen, se range aux arguments de Duns Scot concernant les baptêmes forcés d'enfants, après avoir passé en revue les principales opinions proposées sur ce point. Biel se montre en revanche plus prudent en ce qui concerne les baptêmes forcés d'adultes, notamment en raison des dangers que de faux convertis pourraient faire courir aux vrais chrétiens ${ }^{86}$. Quelques années plus tard, en 1508, Ulrich Zasius, professeur de droit à Fribourg, fit paraître à Strasbourg un opuscule consacré au problème ${ }^{87}$. Rédigée à l'occasion d'une controverse suscitée par le cas du baptême d'un enfant juif laissé par son père en gage chez des chrétiens, dans l'attente du paiement d'une rançon, cette dissertation récapitule la plupart des arguments soulevés dans les discussions précédentes. Si l'autorité du Docteur Subtil est invoquée en bonne place, ce n'est pourtant pas sa démonstration qui sert de fil conducteur au propos de Zasius, et l'on ne saurait imputer à la seule influence de Duns Scot la réponse qui est donnée, dans une soudaine bouffée de haine, à la prophétie d'Isaïe. Les juifs, dit en somme Zasius, sont assez nombreux dans les contrées infidèles pour qu'il n'y ait pas à craindre que "périsse la semence d'Israël” si l'on

86 GABRIEL BIEL, Collectorium in IV libros sententiarum Guillelmi Occam, Tübingen, 1501, reprint Hildesheim, Olms, 1977 (non paginé), Lib. IV, d. IV, q. 2, dubium 5. Voir notamment : " plus possunt nocere ecclesie infideles occulti quam manifesti, quia sub simulatione christianitatis possunt veros christianos facilius seducere".

${ }^{87}$ UlRICH ZASIUS, Quaestiones de parvulis Iudeorum baptisandis, Strasbourg, Gruniger, 1508. A propos de ce texte, voir les commentaires de G. KISCH, “ Toleranz und Menschenwürde ” (art. cit. note 55). 
baptisait de force tous ceux qui demeurent en terre chrétienne ${ }^{88}$.

Parmi les auteurs sur lesquels s'appuie Zasius figurent un certain nombre de franciscains italiens. Angelo Carletti (Angelus de Clavasio) est l'un de ceux dont l'influence fut sans doute la plus forte, en raison de la diffusion de sa Summa, imprimée pour la première fois en 1485 et constamment rééditée dans les années suivantes. Dans son chapitre sur le baptême, la question des enfants juifs est traitée suivant l'opinion de Scot. Angelo se range également à son avis quant aux baptêmes forcés d'adultes mais en introduisant une restriction très forte qui vient répondre à la bulle de protection Sicut iudeis. La contrainte ne doit s'exercer qu'indirectement, afin de susciter chez les juifs la volonté de se convertir en rendant leur situation sociale intenable ${ }^{89}$. Il faudra sans doute poursuivre l'enquête, en examinant notamment les argumentaires des campagnes de prédication anti-juives des franciscains italiens au XVe siècle. Pour lors, on trouve chez Cajétan un indice clair de l'impact des propos de Duns Scot. On sait qu'à Padoue, le commentateur de Thomas d'Aquin entrenait un débat constant avec des adversaires scotistes. Ce débat porta aussi sur le point qui nous intéresse. Dans son commentaire de la Somme de théologie, l'article concernant la conversion forcée des infidèles est intégralement consacré à une réfutation de la position de Duns Scot sur le baptême forcé des adultes, quia videtur habere sequaces ${ }^{90}$. Mais la réponse la plus importante est présentée un peu plus loin, à propos du cas des enfants. À la fameuse hiérarchie des puissances qui subordonne, sans recours possible, le droit des parents au droit du prince et de Dieu, Cajétan oppose une dissociation des ordres de la nature et de la grâce. Le conflit n'oppose pas deux instances inégales, mais deux aspects de la même puissance divine, Dieu en tant qu'instituant d'une part la nature et d'autre part la foi. Or puisque “ l'ordre de

\footnotetext{
88 Ibid., cahier C, fol. $3 \mathrm{v}^{\circ}$

89 Angelus De Clavasio, Summa angelica, cum additionibus suis nitidius et castigatius, Paris, Renaud, 1502 , fol. $29 \mathrm{v}$ : “ ... intelligendo de compulsione indirecta, hoc est ita sunt aggravandi et in servitutem redigendi, quod eis eveniat voluntas convertendi ".

90 Thomas de Vio Caietani, Commentarius in Summa Theologiae. Secunda Secundae, q. 10, art. 8 (Leon. VIII p. 89), cité plus haut, note 39.
} 
la grâce parachève et ne détruit pas l'ordre de la nature ", c'est au moyen des lois de la nature que la loi de la foi peut se réaliser. En l'occurrence, la nature requiert que l'adulte puisse atteindre la foi par l'usage de la raison et de la volonté, et l'enfant par l'intermédiaire des facultés de ses parents ${ }^{91}$. Comme on le constate, loin de porter sur un point anecdotique, le débat engage effectivement les clivages les plus forts qui peuvent opposer thomistes et scotistes.

Le débat, relancé de la sorte, a trouvé de nombreux échos dans les écoles espagnoles des XVIe et XVIIe siècles ${ }^{92}$. Domingo Soto, en particulier, attache une grande importance à cette question tum celeberrima, tum subinde gravissima par le biais de laquelle il aborde, dans son commentaire du quatrième livre des Sentences, le problème posé par le baptême des Indiens d'Amérique ${ }^{93}$. De leur côté, les scotistes espagnols paraissent avoir défendu avec une certaine constance la doctrine du baptême forcé, d'autant plus aisément qu'ils pouvaient se targuer d'avoir désormais d'autres exemples à associer à celui de Sisebut. Exposant les thèses scotistes, Gregorio Ruyz peut ainsi ajouter, à la suite du nom du roi wisigoth, ceux des Rois catholiques ${ }^{94}$. Comme on l'a vu, Hickey procède de même. Mais avant ces mentions qui viennent justifier la théorie par les faits, on peut se demander dans quelle mesure les débats doctrinaux n'ont pas eux-mêmes pesé

\footnotetext{
91 Ibid., art. 12, p. 95 : "Et hic autem adiuncta illa maxima Gratia perficit, non destruit naturam et Ordo gratiae perficit, non dissolvit ordinem naturae manifeste apparet primo quod dominium parentum supra filios non est tam ipsorum naturae ac Dei qui illam instituit. Ac per hoc, comparatio non est facienda inter parentes et Deum, sed inter Deum institutorem naturae et seipsum Deum institutorem fidei ; uterque enim ordo ab ipso et ipsius est. Apparet secundo quod Deus non sic legem fidei instituit ut voluerit pro ea servanda legem naturae solvi, quamvis hoc posset; sed instituit ut per media secundum naturae ordinem instituta lex fidei impleatur ; ut patet ex maxima allegata ; et in communi, quia divina sapientia disponit omnia suaviter et infima per media reducit in summum; et in proposito quia statuit ut adultus media propria ratione ac voluntate legem fidei impleat, quia suae curae naturaliter commissus est, puer autem media ratione et voluntate parentum, quorum curae naturaliter commissus est. "

92 Voir par ex. F. SuAREZ, Commentaria ac disputationes in tertiam partem D. Thomae, Opera Omnia, t. 20, Paris, Vivès, 1860, p. 420-431; G. VAZQUEZ, Commentariorum ac disputationum in tertiam Partem S. Thomae, Ingolstadt, 1613, disp. 155, p. 506-515.

93 D. Sото, In quartum Sententiarum, Venise, I. M. Lenum, 1575, p. 290-299.

94 G. RuYZ, Controversiae Theologicae in totum quartum Sententiarum Scoti, Valladolid, Godinez a Millis, 1613, p. 108-115.
} 
sur le cours des événements. Une enquête minutieuse serait requise pour apporter une réponse circonstanciée. On dispose toutefois d'un indice important qui montre que les thèses de Duns Scot sur la question ont pu inspirer la prédication anti-juive dans les décennies qui précèdent l'expulsion de 1492. Le Fortalitium fidei du franciscain Alonso de Espina, composé à Valladolid autour de 1460, publié pour la première fois à Strasbourg en 1470 et fréquemment réédité dans les années suivantes contient, dans sa douzième considération sur le sort des juifs, au titre de leur conversion, un résumé fidèle de la question de Scot. Outre la large diffusion qu'a connue cet écrit, principalement dans la péninsule ibérique et en Rhénanie, on peut noter qu'il est le premier, à notre connaissance, qui reprenne explicitement le thème du cantonnement dans une île ${ }^{95}$.

L'édit d'expulsion des juifs d'Espagne du 31 mars 1492 constitue le point d'aboutissement des campagnes de conversions massives menées depuis la fin du XIVe siècle $^{96}$. Les Rois catholiques y justifient en effet l'expulsion, en termes très explicites, par la crainte de la "contagion" et le souci de soustraire les nouveaux chrétiens aux séductions du judaïsme ${ }^{97}$. L'expulsion des juifs apparaît ici comme la conséquence nécessaire de la politique de conversion des souverains espagnols, et non comme la seconde branche d'une alternative entre conversion et expulsion. La même politique sera appliquée au Portugal en 1496, puis en Navarre en 1498, mettant un terme à la présence des juifs sur le sol ibérique.

Si l'édit d'expulsion du Portugal ${ }^{98}$, promulgué en décembre 1496, se démarque peu de l'édit espagnol de 1492 dont il reprend succinctement les termes, le cas portugais présente par ailleurs des traits singuliers qui méritent de retenir l'attention. En 1493, le roi

95 Fortalitium fidei contra Judeos, Sarracenos, aliosque Christiane fidei inimicos, Lyon, G. Balsarin, 1487, fol. 235v. Voir, au sujet de ce texte, A. MeYÛHAS GINIO, La Forteresse de la foi. La vision du monde d'Alonso de Espina, moine espagnol, Paris, Cerf, 1998.

96 Au terme des violences perpétrées en 1391, des communautés entières furent détruites et des dizaines de milliers de juifs furent baptisés de force. Cf. Y. H. Yerushalmi, Sefardica. Essais sur l'histoire des juifs, des marranes et des nouveaux chrétiens d'origine hispano-portugaise, Paris, Chandeigne, 1998, p. 24.

97 Cf. B. Leroy, Les édits d'expulsion des Juifs, Biarritz, Atlantica, 1998, p. 29 sq. 
Jean II, qui avait admis pour huit mois les juifs expulsés d'Espagne et promis de les aider à partir, ordonna que ces juifs fussent vendus comme esclaves et contraints à la conversion $^{99}$. En décembre 1493, leurs enfants leur furent enlevés pour être déportés sur l'île de Sao Tomé, découverte par les navigateurs portugais en $1471^{100}$. En décembre 1496, Manuel Ier, successeur de Jean II et époux de la princesse espagnole Isabelle, ordonna aux juifs de quitter le Portugal dans un délai de dix mois. Cependant, voyant les juifs prêts à partir, il leur fit enlever leurs enfants pour les confier à des familles chrétiennes puis, dans l'hiver 1497, leur interdit de quitter le pays et les fit baptiser de force $^{101}$, reproduisant ainsi le processus de 1493.

Certes, la déportation des enfants juifs à Sao Tomé en 1493 ne répondait pas au projet d'y conserver un petit nombre de juifs jusqu'à leur conversion finale. Du reste, d'après les chroniques juives du XVIe siècle, très peu d'enfants survécurent à la déportation et au séjour dans l'île, réputée particulièrement inhospitalière. Prise globalemenent, l'attitude de Manuel Ier, en 1497, témoigne de sa volonté de convertir plutôt que d'expulser les juifs. La conversion forcée apparaît dans ce cas comme le seul moyen dont le souverain portugais disposait pour empêcher leur départ, alors même qu'il s'était engagé envers l'Espagne, à expulser tous les infidèles de son royaume ${ }^{102}$. Il n'en reste pas moins que la déportation des enfants, en 1493, de même que les conversions forcées de 1497, sans équivalent dans la péninsule ibérique depuis l'époque wisigothique, peuvent être considérées comme la mise en œuvre la plus complète du programme de Duns Scot. Par une triste ironie de l'histoire, l'île en question portait le nom de saint

\footnotetext{
98 Ibid., p. 61-63.

99 Cf. A. Novinsky, "Juifs et nouveaux chrétiens du Portugal”, in H. Mechoulan dir., Les juifs d'Espagne : histoire d'une diaspora. 1492-1992, Paris, L. Levi, 1992, p. 80.

100 Cet épisode est relaté, en particulier, dans le Seder Eliahou Zouta, Chronique de l'expulsion (1523), présentation, traduction et annotation par S. SULTAN-BонBOT, Paris, Cerf, 1994, p. 135-136 et dans la Vallée des pleurs de Joseph HA-COHEN (vers 1560), tr. de l'hébreu par J. SÉE, Paris, Centre d'études Don Isaac Abravanel, 1981, p. 104.

101 Cf. A. NOVINSKY, loc. cit., p. 81.

102 Ibid.
} 
Thomas $^{103}$.

\section{Annexe : Établissement du texte}

L'intérêt que présente cette brève question méritait qu'elle soit rendue accessible en annexe de ce travail. Nous avons tenté d'en établir le texte en nous appuyant sur les deux témoins les plus fréquemment employés par les éditeurs de Duns Scot - Assise, Bibl. Com., $136^{104}$ et Oxford, Merton College, 66 - qui représentent l'un et l'autre des versions de l'Ordinatio relue et corrigée par des élèves ou des proches du maître, peu après à son décès. Nous avons également tenu compte des cinq plus anciens manuscrits disponibles à la Bibliothèque Nationale de France. En raison du nombre trop important de variantes singulières qu'il comporte, le cod. Paris, BNF, lat. 15854 a finalement été écarté de l'apparat critique. Les manuscrits employés dans l'édition sont désignés par les sigles suivants :
A: Paris, BNF, lat. 3062.
B : Paris, BNF, lat. $3114-2$.
C : Paris, BNF, lat. 12332.

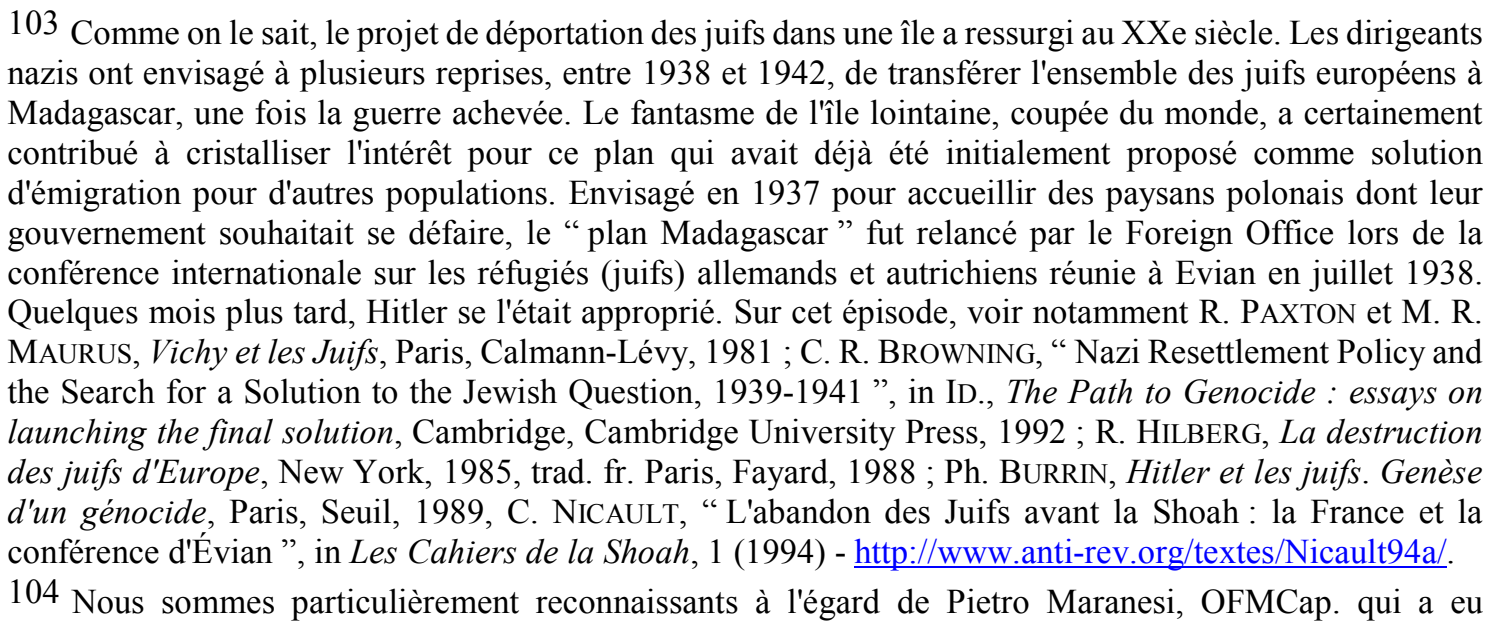


D : Paris, BNF, lat. 15361.

M : Oxford, Merton College, cod. 66.

S : Assisi, Biblioteca Comunale, cod.136.

La taille trop réduite de l'échantillon examiné ne permet de formuler aucune conclusion générale quant à la tradition textuelle du quatrième livre de l'Ordinatio. Nous avons accordé la préférence aux leçons de $\mathbf{S}$ en adoptant la graphie de ce manuscrit qui peut à juste titre être pris comme témoin de base ${ }^{105}$. Nous ne l'avons laissé de côté qu'en deux cas seulement. S'il présente le texte le plus satisfaisant, il faut toutefois signaler qu'il s'écarte souvent de façon notable des autres témoins. Parmi ces derniers, le témoin D nous a semblé le plus intéressant représentant d'une tradition universitaire parisienne. Afin de faciliter le travail des chercheurs, il a semblé utile de rappeler le texte de l'édition Wadding (sigle W).

\section{Johannes Duns Scotus, Ordinatio in IV Sent., dist. 4, qu. 9}

De parvulis iudeorum et infidelium, an sint invitis parentibus baptizandi.

Dicitur quod non, quia aut redderentur parentibus, et tunc baptizacio eorum esset in contumeliam fidei christiane, quia post nutrirentur a parentibus in errore parentum, aut non redderentur, et tunc fieret eis ${ }^{106}$ iniuria, quia dum sunt ${ }^{107}$ parvuli, ius habent parentes in eis ${ }^{108}$.

Sed hec ratio, licet forte concludat de quacumque persona privata, quod non

l'amabilité de nous transmettre une reproduction des deux feuillets de ce manuscrit contenant la question.

105 La qualité de ce manuscrit, reconnue depuis longtemps dans les études scotistes et les améliorations qu'il permet d'apporter au texte de l'Ordinatio sont telles que l'on souhaiterait pouvoir disposer, dans l'attente d'une édition complète longue à venir, de solutions transitoires, que ce soit une transcription simple de ce manuscrit ou une reproduction fac-similé consultable par Internet.

106 eis] om. $\mathrm{A}+\mathrm{W}$

107 sunt] fuerunt, $\mathrm{C}$

108 eis] eos, M ; opinio Tho. et Richardi, adnot. in mg. C 
posset $^{109}$ parvulos a talibus auferre ${ }^{110}$ iuste et baptisare ${ }^{111}$, non videtur tamen concludere de principe, cui in regimine rei publice tales sunt subditi. Nam in parvulo deus ${ }^{112}$ habet maius ius dominii quam parentes. Universaliter enim in potestatibus ordinatis ${ }^{113}$, potestas inferior non obligat in hiis que sunt contra superiorem, sicud docet Augustinus De verbis ${ }^{114}$ Domini, omelia sexta, et ponitur capitulo ultimo secundi libri : Si illud ${ }^{115}$ iubet potestas quod non debes ${ }^{116}$ facere, hic sane contempne potestatem ${ }^{117}$, timendo potestatem maiorem, et declarat in exemplo ${ }^{118}$ de curatore et proconsule, et imperatore et deo $^{119}$. Igitur qui ${ }^{120}$ habet regere rem publicam, magis debet ${ }^{121}$ cogere unumquemque subdi domino superiori quam inferiori, immo ${ }^{122}$ superiori contempto inferiori, quando ${ }^{123}$ inferior in ${ }^{124}$ tali dominio resistit superiori ${ }^{125}$. Sicud si $^{126}$ imperator deberet ${ }^{127}$

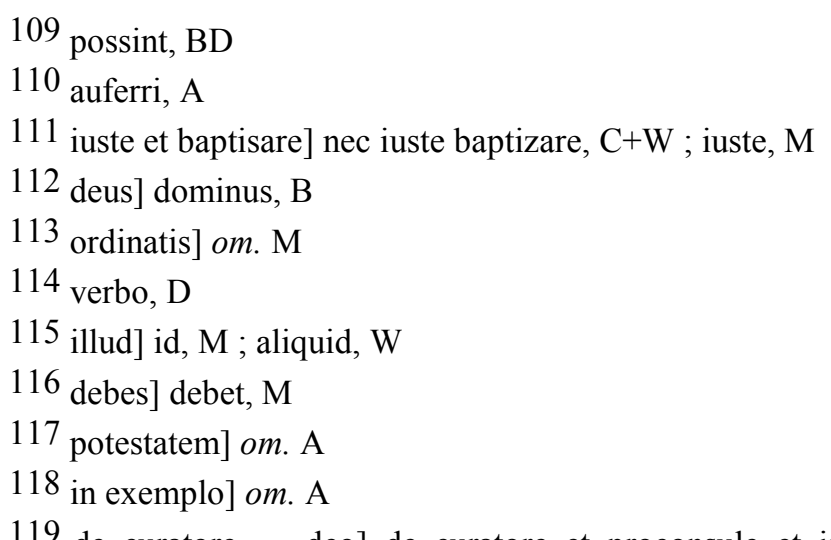

119 de curatore ... deo] de curatore et proconsule et imperatore, $\mathrm{S}$; de curatore et pronconsule et imperatore, et de imperatore et deo, BM; de curatore et proconsule (consule, $\mathrm{C}$ ), de proconsule et imperatore, de (et, C) imperatore et deo, AC + W ; cf. Augustinus, Sermo VII, 13 (PL 38, c. 420-421) repris dans le Décret : Grat. 11, 3, 97

120 qui] si quis, $\mathrm{A}+\mathrm{W}$; hic qui, $\mathrm{B}$

121 quantum in se est, add. $\mathrm{W}$

122 ergo qui habet ... immo] scr. in mg. D

123 quando] quia, $\mathrm{S}$

124 in] om. B

125 quam inferiori ... resistit superiori] om. C ; ergo qui habet regere rem publicam magis debet cogere unumquemque subditum domino superiori, add. $\mathrm{D}$

126 si] ergo, $\mathrm{M}+\mathrm{W}$

127 deberet] debet, $\mathrm{M}$ 
sentenciare $^{128}$ aliquem obedire debere proconsuli, contempto precepto curatoris, id est inferioris proconsule, si contradiceret proconsuli. Ita etiam si essent sub eodem dominia $^{129}$ ordinata, scilicet quod aliquis esset servus Ticii, et Ticius Petri, magis deberet imperator cogere illum servum ${ }^{130}$ servire Petro, quia superior est Ticio, quam Ticio, si Ticius vellet uti ${ }^{131}$ servo illo ${ }^{132}$ contra dominium Petri. Igitur maxime debet princeps zelare pro dominio ${ }^{133}$ servando suppremi domini, scilicet dei, et per consequens non solum licet, sed et ${ }^{134}$ debet princeps auferre parvulos a dominio parentum volencium eos educare contra cultum dei, qui est supremus et honestissimus dominus, et debet eos applicare cultui divino.

Dico ergo breviter quod si princeps hoc faceret cum cautela bona, scilicet ne parentes hoc cognoscentes in futurum ${ }^{135}$ occiderent parvulos ${ }^{136}$, et quod baptizatos facerent ${ }^{137}$ religiose educari, bene fieret. Immo quod plus est, crederem ${ }^{138}$ religiose fieri si ipsi parentes cogerentur minis et terroribus ad suscipiendum ${ }^{139}$ baptismum et ad servandum ${ }^{140}$ postea susceptum. Quia esto quod ipsi non essent omnes ${ }^{141}$ fideles veri ${ }^{142}$

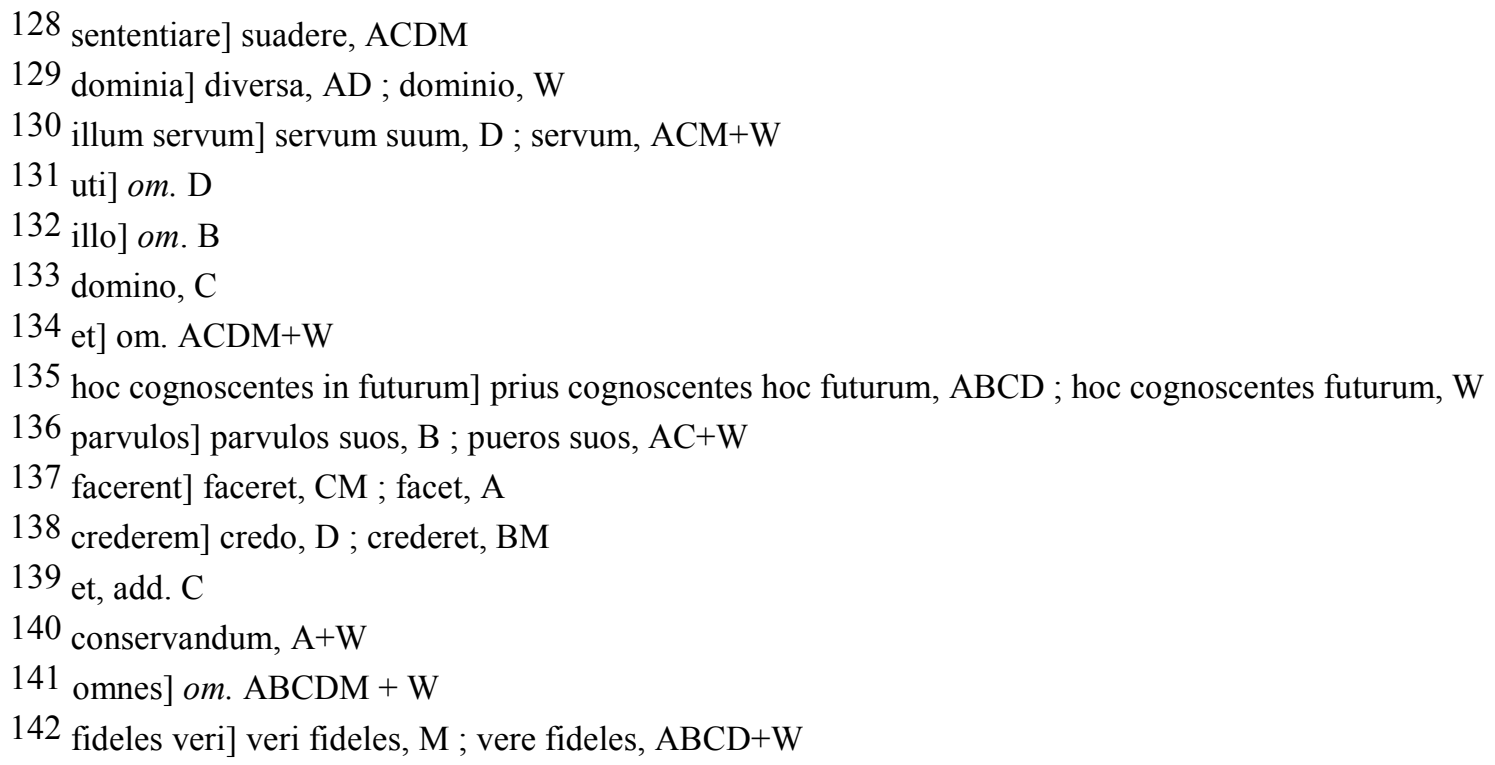


in animo ${ }^{143}$, tamen minus malum esset ${ }^{144}$ eis non posse impune legem suam illicitam ${ }^{145}$ servare, quam posse eam libere servare. Item filii eorum, si bene educarentur, in tertia et quarta progenie essent vere fideles.

$\mathrm{Si}^{146}$ dicas quod secundum Ysaie prophetiam quam recitat Paulus, Ad Romanos ${ }^{147}$ [9 : 27], reliquie Israel convertentur in fine, et ideo iudeos ${ }^{148}$ non oportet cogi ${ }^{149}$ totaliter ad baptismum suscipiendum ${ }^{150}$ et relinquendum legem suam, respondeo, non dubito quin vera sit prophetia Christi, quam recitat Christus Joan. 5 [43]: Ego veni in nomine patris mei, et non accepistis me ; si alius venerit in nomine suo ${ }^{151}$, illum suscipietis ${ }^{152}$. Igitur, ad minus ex verbo Christi erunt pervertendi, quia adherebunt illi pessimo antichristo, de quo est sermo Christi ${ }^{153}$ predictus.

Et si dicas quod visa destructione Antichristi, illi qui sibi adheserant convertentur, dico quod pro ita ${ }^{154}$ paucis et sic tarde convertendis, quia ${ }^{155}$ modicus erit fructus ecclesie, et ${ }^{156}$ de quibus nulla erit propagacio filiorum in lege christiana ${ }^{157}$, non oporteret ${ }^{158}$ tot iudeos, in tot partibus mundi, tantis temporibus sustinere in lege sua ${ }^{159}$ perstare $^{160}$, sed ${ }^{161}$

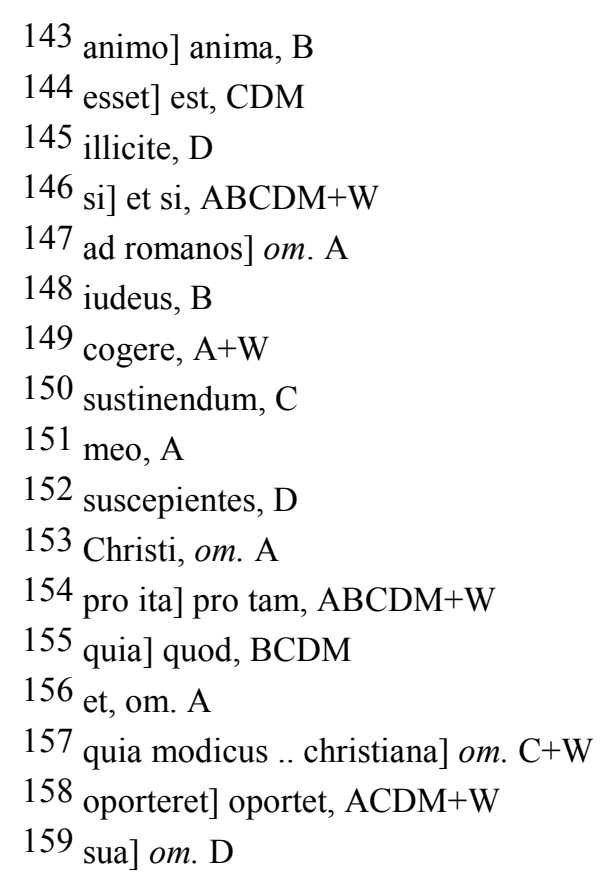


sufficeret aliquos paucos in aliqua insula sequestratos ${ }^{162}$ permitti legem suam $^{163}$ servare, de quibus tandem illa prophetia Ysaie impleretur.

Istud autem de parentibus infidelibus cogendis ${ }^{164}$ per minas et terrores videtur probari, quia simile illud concilium Tolletanum commendat supra allegatum dicens : Qui pridem ad christianitatem coacti ${ }^{165}$ sunt, sicud factum est temporibus religiosissimi principis $^{166}$ Syssebuti $^{167}$. Igitur in hoc approbat eum tanquam principem religiosum, quia $^{168}$ coegit $^{169}$ infideles ad fidem.

Elsa Marmursztejn, Université de Reims

Sylvain Piron,Ecole des Hautes Etudes en Sciences Sociales

160 perstare] persistere, $\mathrm{M}+\mathrm{W}$; quia finalis fructus de eis ecclesie erit (est et erit, $\mathrm{C}+\mathrm{W}$ ) modicus, add. $\mathrm{BCDM}+\mathrm{W}$

161 sed] unde, $\mathrm{ABCDM}+\mathrm{W}$

162 sequestratos] sequestracionis, $\mathrm{C}$

163 suam] om. M

164 cogendum, D

165 cogendi, B

166 principis] om. D

167 Assebuti, BD ; Assueri, A ; cf. Grat. 45, 5 (ed. Friedberg, I, 161-162)

168 quia] qui, A ; quod, B

169 coegit] cogeret, $\mathrm{D}$; cogit, $\mathrm{M}+\mathrm{W}$ 